\title{
Sources of IR Radiation in the Earth's Atmosphere in Connection with the PeTa Effect
}

\author{
Vitali A. Tatartchenko \\ CNRS, University of Aix-Marseille, Marseille, France \\ Email: vitali.tatartchenko@orange.fr
}

How to cite this paper: Tatartchenko, V.A. (2021) Sources of IR Radiation in the Earth's Atmosphere in Connection with the PeTa Effect. Optics and Photonics Journal, 11, 152-196.

https://doi.org/10.4236/opj.2021.116013

Received: May 6, 2021

Accepted: June 26, 2021

Published: June 29, 2021

Copyright $\odot 2021$ by author(s) and Scientific Research Publishing Inc. This work is licensed under the Creative Commons Attribution International License (CC BY 4.0).

http://creativecommons.org/licenses/by/4.0/

\begin{abstract}
The PeTa (Perelman-Tatartchenko) effect is the radiation of the energy of a first-order phase transition during the transition from a less condensed phase to a more condensed one. The effect was independently discovered by $\mathrm{M}$. Perelman and the author of this paper. Six papers on the PeTa effect have been published in this journal over the past nine years. They are devoted to the development of PeTa models to explain the following phenomena: IR radiation from cold surfaces, cavitation luminescence/sonoluminescence (CL/SL), laser-induced bubble luminescence (LIBL), and vapor bubble luminescence (VBL) in underwater geysers. This paper describes the sources of PeTa radiation in the Earth's atmosphere. These sources of infrared radiation have been investigated by numerous research groups, but their interpretation either does not exist at all, or it is erroneous. The following phenomena are specifically considered: PeTa radiation during the formation of clouds and fog; a pulse laser based on the PeTa radiation; condensation explosions as sources of PaTa radiation; measurement of the concentration of water vapor in the atmosphere using PeTa radiation; atmospheric scintillation of infrared radiation in the atmosphere due to the PeTa effect; PeTa radiation as a source of comfort for the igloo; the influence of PeTa radiation on living organisms; $\mathrm{PeTa}$ radiation due to characteristics of tropical storms; PeTa radiation as a possible precursor to earthquakes. The problem of global warming, which worries everyone, as it turns out, is also associated with the PeTa effect.
\end{abstract}

\section{Keywords}

PeTa (Perelman-Tatartchenko) Effect, Sources of PeTa Radiation in the Earth's Atmosphere, Pulse IR Laser, Condensation Explosions, Atmospheric IR Scintillations, Tropical Storms, Earthquakes, Global Warming 


\section{Introduction}

The PeTa effect is the radiation of the energy of a first-order phase transition during the transition from a less condensed phase to a more condensed one. $M$. Perelman as well as the author of this paper identified the effect independently. Prior to the work of these researchers, it was believed that this energy can be removed only through heat conductivity. M. Perelman predicted the effect theoretically [1]. V. Tatartchenko proved its existence experimentally during the crystallization of several alkali halides [2] [3] and sapphire [4]. The experimental results of $\mathrm{V}$. Tatartchenko were published with a great delay due to the strong resistance of opponents of this effect. In 2010, M. Perelman died. In memory of Professor Perelman, the term PeTa (Perelman-Tatartchenko) effect is used in this paper as suggested in the discussion of this problem in the journal "New scientists" [5].

Six papers devoted to the PeTa (Perelman-Tatartchenko) effect have been published in this journal over the past nine years. They are devoted to the development of PeTa models to explain the following phenomena: IR radiation from cold surfaces [6] [7], cavitation luminescence/sonoluminescence (CL/SL) [8], laser-induced bubble luminescence (LIBL) [9] [10], vapor bubble luminescence in underwater geysers (VBL) [11]. This paper describes the sources of $\mathrm{PeT}$ Ta radiation in the earth's atmosphere.

The following phase transitions with the participation of water vapor, water, and ice can occur in the earth's atmosphere: 1) Condensation of water vapor with the formation of clouds and fog; 2) Freezing of water droplets with the formation of the hail; 3) Deposition of water vapor with the formation of snow; 4) Condensation of vapor on the surfaces of tiny water droplets that are too small to form fog; 5) Evaporation from the surface of these small droplets. The first four processes occur with the emission of PeTa radiation. In the simplest cases, the wavelength of PeTa radiation can be estimated by formulas (3)-(5) from [8] and (5) from [9]. Estimates made using these formulas show that for our case, PeTa radiation lies mainly in the IR range, in the atmospheric transparency window of $6.5-14 \mu \mathrm{m}$.

In 1990, R. Lindzen, Professor of Meteorology at MIT, wrote: "Water vapor in the atmosphere contributes $60 \%-70 \%$ of the greenhouse effect, while carbon dioxide contributes $25 \%$...Given the predominant role of water vapor in tropospheric radiation...it is clear that our current knowledge of the behavior of water vapor does not correspond to the existing task" [12]. This paper shows that the PeTa effect can explain many hitherto incomprehensible phenomena in the Earth's atmosphere: IR radiation during the formation of clouds and fog ( $\$$ 2 ); IR radiation recorded by sensitive radiometers from satellites $(\$ 3)$; Condensation explosions $(\$ 4)$; Measurements of the concentration of water vapor in the atmosphere due to the IR radiation $(\$ 5)$; Atmospheric IR scintillations $(\$ 6)$; IR radiation and living organisms $(\$ 7)$; IR characteristics of tropical storms $(\$ 8)$; VBL-vapor bubble luminescence $(\$ 9)$; IR radiation preceding earthquakes $(\$$ 
$10) ;$ PeTa effect and global warming ( $\$ 11)$. Thus, our knowledge of the behavior of water vapor will be greatly expanded.

\section{IR Radiation during the Formation of Clouds and Fog}

In [13], the authors reported that they have developed an infrared camera that scans an object linearly in three separate spectral ranges simultaneously and creates an image of the object in the form of a color photograph. Three detectors: $\mathrm{Si}, \mathrm{InSb}$, and $\mathrm{Ge}$ were respectively used for the following spectral regions: $0.5-1.0 \mu \mathrm{m}, 3.0-5.5 \mu \mathrm{m}$, and $8-14 \mu \mathrm{m}$. The last two detectors were cooled with liquid nitrogen. Each of the infrared spectral bands mentioned above has been displayed in one of the colors: blue, green, and red, respectively. As a result, according to the authors, the color of the objects in the picture indicates their radiation temperature, as well as their reflective and radiative properties. Several images presented by the authors (Figure 8a, b from [6]; Figure 1(a), Figure 1(b) and Figure 2(a), Figure 2(b)) suggest that they actually detected atmospheric sources of infrared radiation, which are in the range of $8-14 \mu \mathrm{m}$ and cannot be associated with either temperature or reflected radiation.

These sources correspond to the underside of forming (Figure 8a, b from [6]) and dissipating (Figure 1(a), Figure 1(b)) cumulus clouds with a temperature of $-5^{\circ} \mathrm{C}$ and rising warm air saturated with water vapor (Figure 2(a), Figure 2(b)). On dry, clear days, the last radiation was not so obvious. It should be noted that the authors did not find unusual IR radiation either in the $0.5-1.0 \mu \mathrm{m}$ range or in the 3.0 - $5.5 \mu \mathrm{m}$ range. Nichols and Lamar write: "The true origin of the $8-14$ micron radiation is unknown." Nevertheless, PeTa emission during cloud (Figure $8 \mathrm{a}, \mathrm{b}$ from [6]) or fog (Figure 2(a), Figure 2(b)) formation, as well as dispersion of cumulus clouds (Figure 1(a), Figure 1(b)), is the only obvious plausible explanation for this phenomenon.

It is surprising that these interesting studies, carried out more than 50 years ago, have not been developed. This is probably because PeTa radiation exists only during condensation, i.e. during the formation of clouds, while the clouds reflect the long-wave radiation coming from the earth's surface into space both during its formation and after. This process masks the PeTa effect. But even on the basis of work [13], it can be said that the study of the radiation of clouds in the spectral range of $8-14 \mu \mathrm{m}$ and the comparison of this radiation with radiation in other spectral intervals could clarify the problem.

However, it is interesting to know what modern meteorology has to say about the effect of clouds on the earth's radiation balance. This effect is called radiative forcing [14]. Quantification of the global distributions of cloud radiative forcing was obtained from the Earth Radiation Balance Space Experiment (ERBE), which began in 1984. In April 1985, it was found that the reflection of shortwave solar radiation was $-44.5 \mathrm{~W} / \mathrm{m}^{2}$. At the same time, the reflection of long-wave radiation from the earth (greenhouse effect) was $31.3 \mathrm{~W} / \mathrm{m}^{2}$. Thus, the clouds had a pure cooling effect on the earth. 


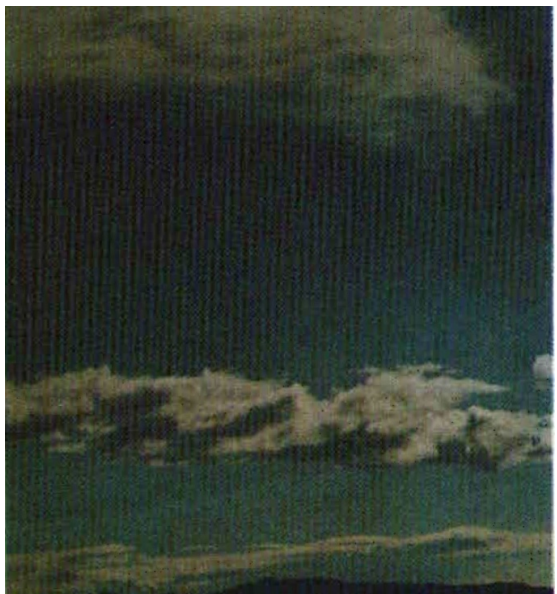

(a)

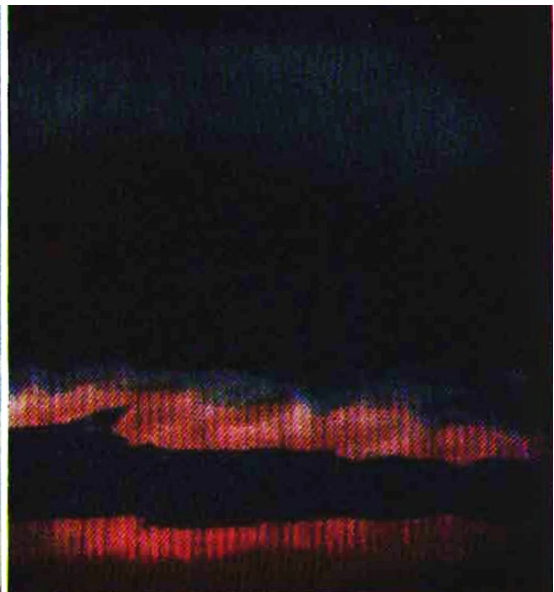

(b)

Figure 1. From [13]. Photographs of a scattering cumulus cloud in different wavelength ranges: (a) visible range; (b) Infrared range 8 - $14 \mu \mathrm{m}$.

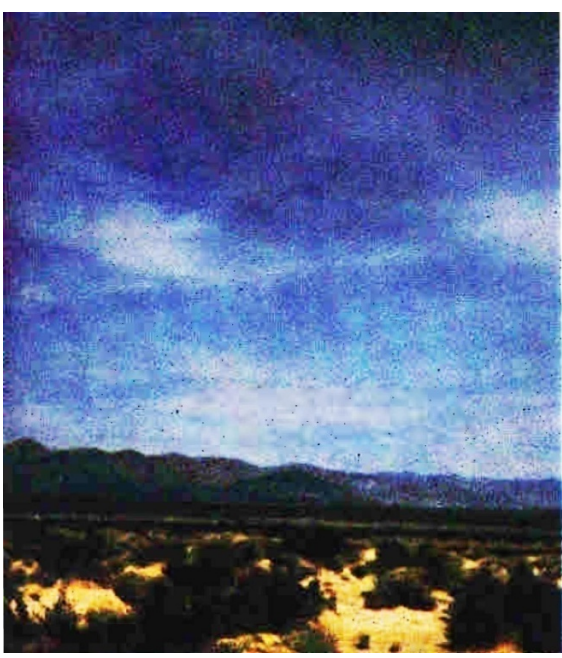

(a)

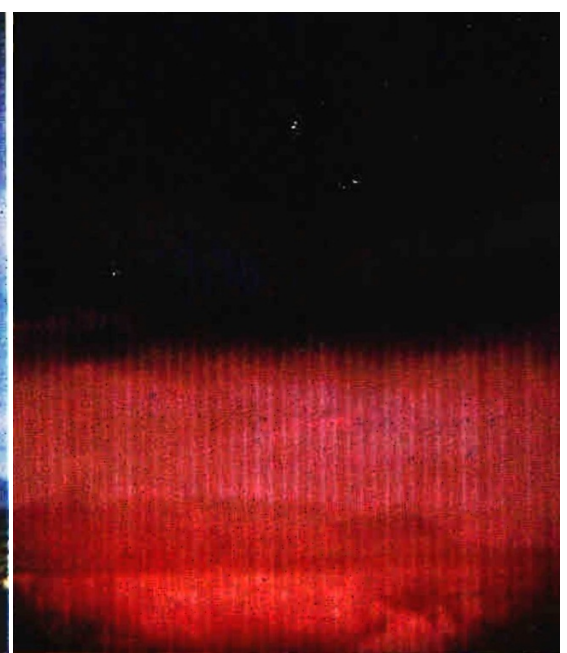

(b)

Figure 2. From [13]. The photograph was taken in the desert on a warm and humid day in different wavelength ranges: (a) visible range; (b) Infrared range $8-14 \mu \mathrm{m}$.

This cooling effect is especially strong in the middle and high latitudes over the oceans, and its values reach $-100 \mathrm{~W} / \mathrm{m}^{2}$. The average monthly value of longwave radiation reaches maximum values from 50 to $100 \mathrm{~W} / \mathrm{m}^{2}$ in convectively disturbed regions of the tropics. However, this heating effect is almost offset by the corresponding large negative effect of clouds on shortwave radiation, indicating a delicately balanced state of the tropics. The observed net cloud forcing is about four times the expected radiative forcing from a doubling of $\mathrm{CO}_{2}$. Hence, small changes in cloud radiative forcing can play an important role as a climate feedback mechanism. For example, during past glaciations, the migration to the equator of a field of strong negative cloud radiative forcing in response to a similar migration of colder waters could significantly enhance oceanic cooling and continental glaciation. 


\section{IR Radiation Recorded by Sensitive Radiometers from Satellites}

Detected by satellites, infrared radiation allows getting very important information concerning the atmosphere and processes on the earth's surface. But the interpretation of infrared images is always unproven. An anomalous distribution of infrared radiation had been found and was described by several groups of scientists in the series of papers [15]-[31]. Initial data were obtained with the AVHRR (Advanced Very High Resolution Radiometer) from "The Satellite Active Archive NOAA". The first AVHRR was a 4-channel radiometer, carried on TIROS-N (launched October 1978). This was subsequently improved to a 5channel instrument (AVHRR/2) that was initially carried on NOAA-7 (launched June 1981). The AVHRR/3, with 6 channels, first carried on NOAA-15 (launched in May 1998), was used in these studies (see Table 1).

Of course, we exclude from consideration the thermal anomalies caused by hydrothermal springs and volcanic activity. Only anomalies which in our view are the result of the PeTa radiation during cloud and fog formation will be analyzed. It is evident that the piquancy of the situation lies in the fact that satellite data cannot be explained by existing models without taking the PeTa effect into consideration. However, the authors of the above papers (geologists and geochemists) try to insert the data in the old framework with help of features of the geological structure of the regions of the globe where the thermal anomalies are detected. Besides, it is very strange that the authors of the papers under consideration have been using the term "anomaly". In the end, if the phenomenon can be explained by existing physical concepts, it is not an anomaly. But we leave on the conscience of the authors an answer to this rhetorical question.

To begin with, we will consider the paper [15] which represents in detail a procedure of treatment of satellite data. The southern part of Eastern Siberia was the region of investigation in the paper. It should be noted that the geothermal environment of this area has been well studied: there are many geophysical ground surveillance stations, many deep-drilled wells, in which the temperature

Table 1. AVHRR/3 Channel Characteristics.

\begin{tabular}{cccc}
\hline & \multicolumn{3}{c}{ AVHRR/3 Channel Characteristics } \\
\hline $\begin{array}{c}\text { Channel } \\
\text { Number }\end{array}$ & $\begin{array}{c}\text { Resolution } \\
\text { at Nadir }\end{array}$ & $\begin{array}{c}\text { Wavelength } \\
(\mu \mathrm{m})\end{array}$ & Typical Use \\
\hline 1 & $1.09 \mathrm{~km}$ & $0.58-0.68$ & Daytime cloud and surface mapping \\
2 & $1.09 \mathrm{~km}$ & $0.725-1.000$ & Land-water boundaries \\
$3 \mathrm{~A}$ & $1.09 \mathrm{~km}$ & $1.58-1.64$ & Snow and ice detection \\
$3 \mathrm{~B}$ & $1.09 \mathrm{~km}$ & $3.55-3.93$ & Night cloud mapping, sea surface temperature \\
4 & $1.09 \mathrm{~km}$ & $10.3-11.3$ & Night cloud mapping, sea surface temperature \\
5 & $1.09 \mathrm{~km}$ & $11.5-12.5$ & Sea surface temperature
\end{tabular}


distribution is well measured [16]. The author of the paper [15] formulates his task: Establishment of infrared radiation contours and accurate geographic coordinates; measurement of radon activity in the areas of infrared anomalies; link of the infrared anomalies with other geological parameters: vegetation index, radon activity, and relief.

Probably, we need an explanation of the meaning of a vegetation index (a measure of vegetation intensity). The author used NDVI (Normalized Difference Vegetation Index), the relative normalized vegetation index-a simple measure of the amount of photosynthetic active biomass. A vegetation index qualitatively reflects the fact that the vegetation well absorbs light in the visible range and is worse in the near-infrared range of the spectrum.

Data from the AVHRR were processed using a specialized package. An area, date, and time of reception were selected. From the values of brightness, the radiant temperature and vegetation index were calculated. To clarify the spatial distribution of infrared anomalies, a comparison with the lay of the land was implemented. The heat map was superimposed on a three-dimensional map of the terrain. Therefore, according to the data from the device AVHRR, a distribution of the heat flow in areas of the Baikal Rift Zone (Tunkin depression and Barguzin depression) in the 4th channel (10.30 - $11.30 \mu \mathrm{m}$, maximum flow of energy from the earth) for the period 1998 to 2001 was obtained. In parallel, the data from the 1st and 2nd channels were used for vegetation index calculations. In addition, concentrations of Thoron (Rn-222) and Radon (Rn-220) were measured in the identified infrared anomalies, using the radiometer of Alphaactive gases RGA-01. Here are the main results from this and other abovementioned papers:

Tunka Valley (Figure 3(a), Figure 3(b)). For the determination of the thermal flow from the ground, autumn night images were chosen because the greatest contrast in luminance between the edges and the bottom of the valley was found in these pictures. The maximum radiant temperatures are on the Sayan slopes. It has a value of $8-10 \mathrm{~K}$ higher than the valley itself. The width of this anomaly is $8-10 \mathrm{~km}$. A similar maximum of 6 - $8 \mathrm{~km}$ length is also located on the opposite side of the valley. It has less intensity of $2-3 \mathrm{~K}$ in relation to the south slope. The vegetation Index remains practically unchanged in the valley (Figure $3(c)$ ).

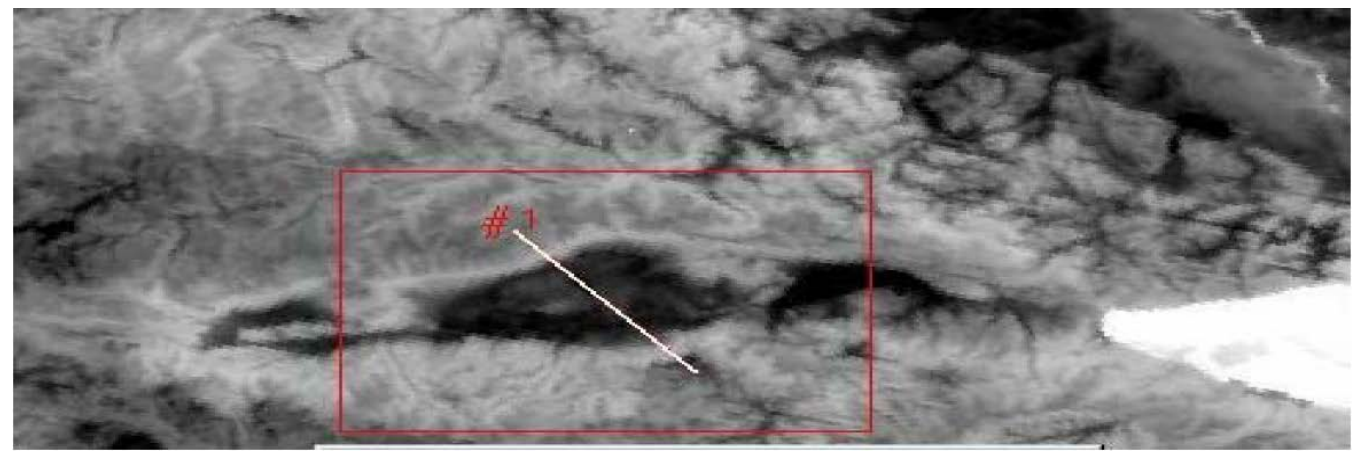

(a) 


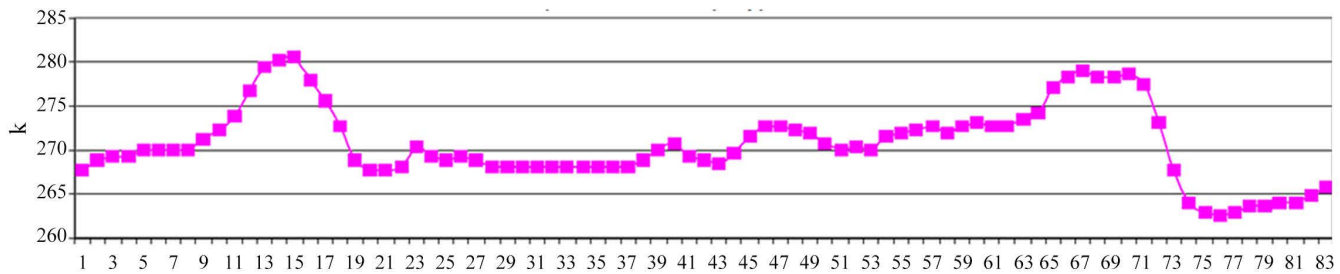

(b)

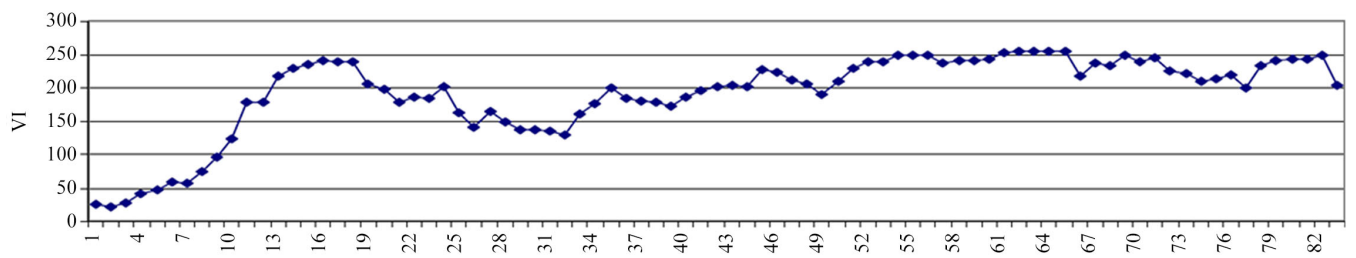

(c)

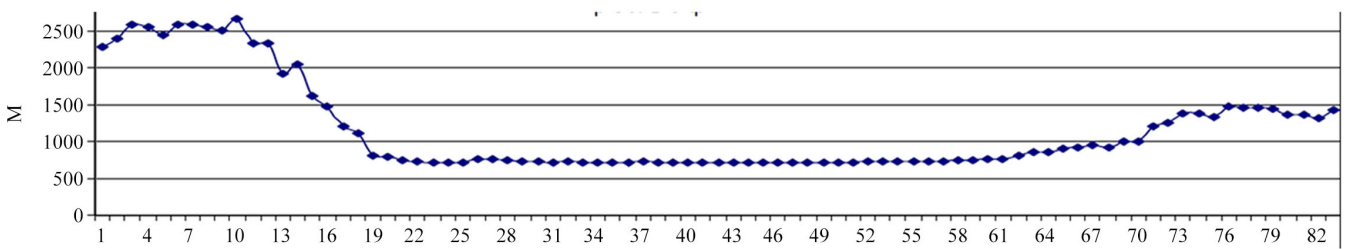

(d)

Figure 3. From [15]; (a) Thermal Photo of Tunka Valley and measuring circuit 1; (b) Values of temperature; (c) Vegetation Index VI; (d) Altitude (All values mark on the circuit 1).

A similar pattern concerning the peculiarities of the heat fields was observed in the Barguzin valley [15], in other tectonic breaks located in the central and south parts of Eastern Siberia, in the Tarim Valley in China [17] [19] [20] [21] [22] [23] (Figures 4(a)-(c)), in the Rhine Graben in Germany [18] (Figure 5), and in the zones of spreading and riftogenesis of the Afar depression in Northeast Africa [23] [24] [25].

The zones of permanent or periodical increase in intensity of the infrared radiation were detected on the images of tectonic breaks located in the western part of the North American continent. The dry climate and low density of forests in this area allowed excluding an influence of the vegetation index on the results of detected brightness. To minimize the daily heat inertia, the only morning data of measurement at 4-5 o'clock of the local time were used [26].

These results allowed the authors to conclude that the anomalies of the earth's infrared radiation at the regions of tectonic breaks have a global character. Four types of anomalies were detected: 1) Linear; 2) Contour; 3) Striped; and 4) Isolated. Respectively, they had the lengths: 1) $200-600 \mathrm{~km}$;) $100-200 \mathrm{~km}$; 40 - $60 \mathrm{~km}$;) $1-1.5 \mathrm{~km}$; and the widths: 1) 5 - $15 \mathrm{~km}$;) $1-6 \mathrm{~km}$; 3) $10-20 \mathrm{~km}$;) $1-1.5 \mathrm{~km}$. Emissions of the 1st, 2nd, and 4th types had a permanent character, and one from the 3rd type was most noticeable during the rain season and became weak in the winter. Some of the anomalies were located in coastal ocean or lake strips, on lake surfaces but most of them were situated on slopes of mountain ranges with an altitude reaching up to $2700 \mathrm{~m}$ above sea level (a.s.l). The last anomalies were narrower for the steeper slopes, and the intensity of their radia- 
tion was distributed in the most contrasting ways on alternate mountain ranges and valleys. The typical values of measured infrared flows [23] were arranged as $50-90 \mathrm{~mW} / \mathrm{m}^{2} \cdot \operatorname{str} \cdot \mu \mathrm{m}$ (Figure $4(\mathrm{~b})$ ).

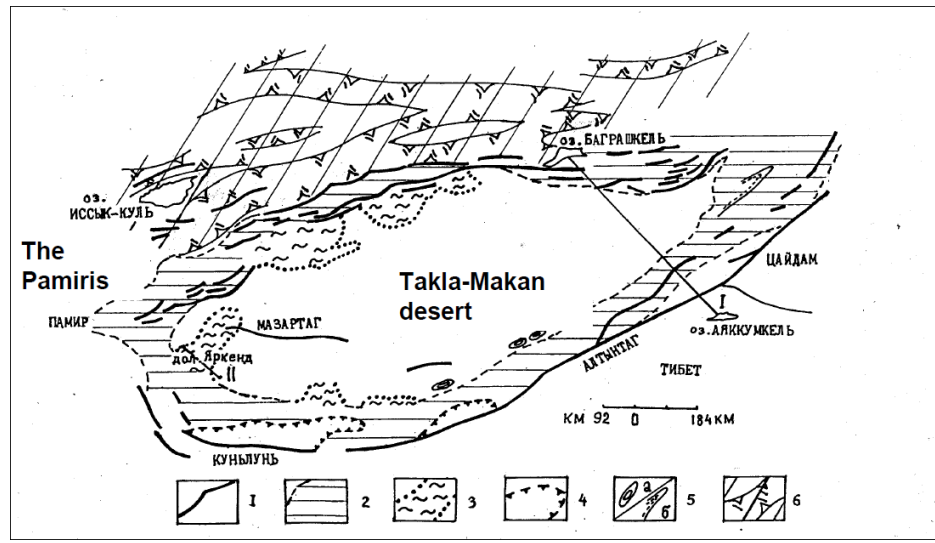

(a)

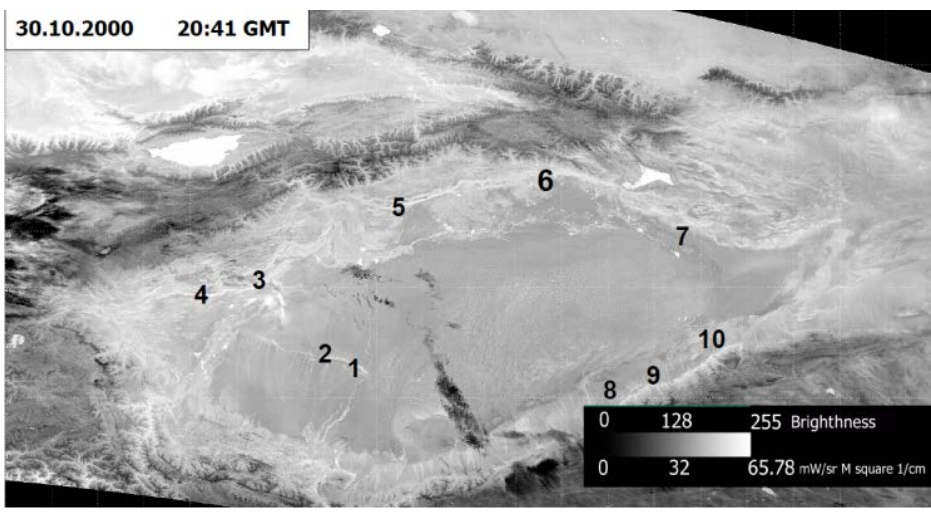

(b)

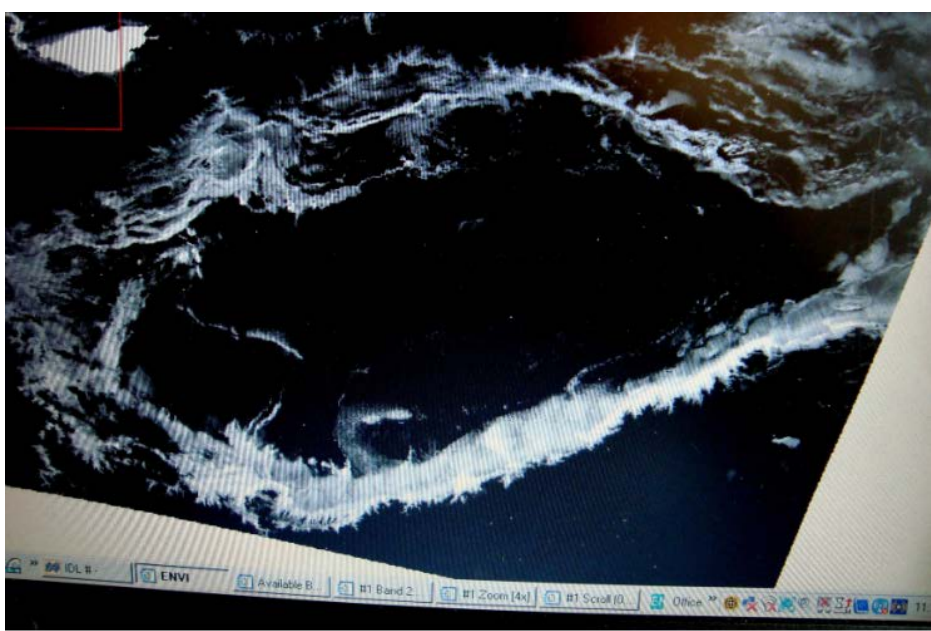

(c)

Figure 4. From [17]; (a) Location of regional faults on the Tarim platform (North-west China, at the top left, Lake Issyk-Kul is located) and its folded margins; (b), (c) Contrast outgoing winter surface IR flow of the Tarim platform and framing, the radiating elements include the Lake Issyk-Kul and others: (b) January 2001 night; (c) October 2000. 


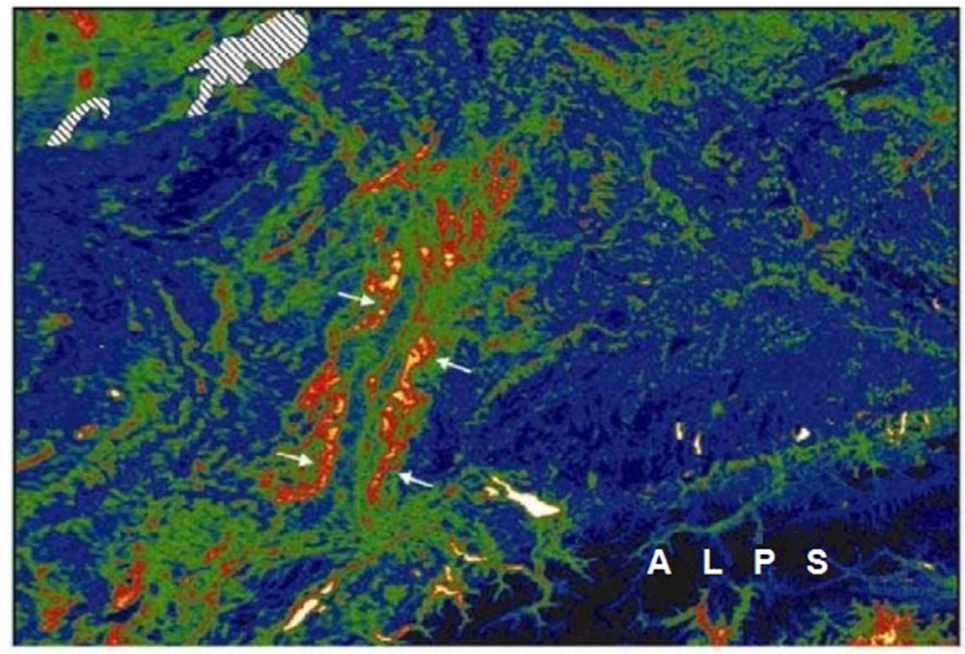

Night temperature contrasts

igure 5. From [18] "Thermal Line" Rhine Graben, card night temperature contrasts-on the satellite survey materials NOAA (AVHRR); arrows indicate positive linear contrasts night surface temperature.

The authors considered several possible sources of the recorded radiation, but first of all, they have explained these anomalies as the result of endogen heat flows exiting through the tectonic breaks. Let us discuss this hypothesis. There are only two ways for the exit of endogen heat: convective or conductive ones. With respect to [18], the convective heat and mass transfer in comparison with conductive heat transfer is a much more efficient mechanism for Earth's internal energy dissipation. For the first time, this mechanism was suggested in the paper [27] to explain the peculiarities of heat exchange in the fault zone near Kopet-Dag.

According to this model (Figure 6), Kopet-Dag fractured limestones are a zone of meteoric water percolation. When reaching heated deep horizons, the temperature of meteoric water rises. Under the action of hydrostatic pressure of a Kopet-Dag fault, the water rises and is unloaded at the level of the groundwater. With respect to opinions of the authors of the papers [18], such a mechanism, based on the difference between the hypsometric levels of infiltration and discharge zones, can explain the occurrence of thermal satellite images_- "thermal lines" for all mountain systems under consideration.

In our opinion, this scheme cannot be implemented. Indeed, hot water rises to the surface under the influence of hydrostatic pressure. This is a simple physical process. But how does cold water penetrate into the depths, overcoming hydrostatic pressure and replacing hot water? The authors call the cause of this process percolation. But it is not applicable in this case, because the only driving force here may be the Laplace pressure in the capillary, and it disappears as soon as the free surface of the liquid in the capillary disappears when the liquid seeping from the surface joins with the liquid in the depths. In other words, the implementation of the process according to the scheme in Figure 6 contradicts the second law of thermodynamics. 


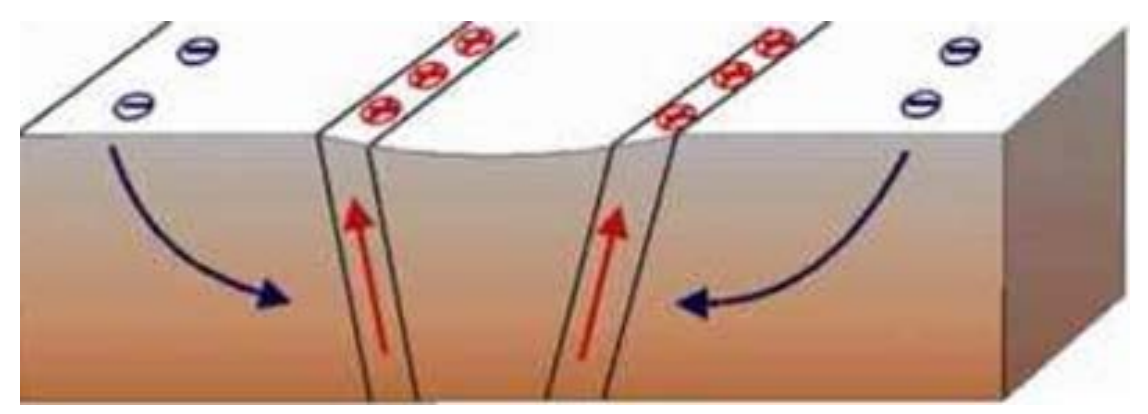

Figure 6. From [18] Model of underground fluids convection in the Rhine Graben.

We offer our own explanation of the observed anomalies. Given that the anomalies are located in places with ideal conditions for fog and cloud formation, it would seem to follow as a natural consequence that the recorded IR radiation is the PeTa emission of water vapor condensation and/or deposition during fog and cloud formation. Indeed:

1) It is not surprising that anomalies are detected in the zones of tectonic breaks because only these zones have been considered in most of the abovementioned papers. At the same time, in [18], the similar "thermal lines" were mentioned in North Karelia, the basin of the White Sea, the Kola Peninsula, the North Arkhangelsk region, and at the foot of the mountains of Kopet Dagh, Urals, Caucasus, and the Himalayas.

2) The analyzed hypothesis of our opponents cannot explain why endogen heat exits on the middle of mountain slopes of altitude ranging between $1000 \mathrm{~m}$ and $2700 \mathrm{~m}$ a.s.l., but not in valleys.

3) The location of anomalies on surfaces of lakes as well as in coastal ocean or lake strips also does not follow the analyzed hypothesis.

4) If we accept the hypothesis of our opponents, the vegetation in the zone of anomalies must be very different from the surrounding one, as it happens near geothermal sources. For instance, in the paper [18], an unusual fact is analyzed: the Big Solovetski island that is located in the very cold White Sea has very intensive vegetation (It is a well-known tourist zone). At the same time, all nearly located islands have the typical poor north vegetation. A good explanation of this phenomenon is the nearly located hydrothermal water which increases the temperature of the internal island's lakes.

5) With respect to the analyzed hypothesis of our opponents, the anomalies have to be very inert. Their hypothesis cannot explain the sensitivity of the anomalies to the seasons and the time of a day, especially in arid climate zones [28].

6) On the other hand, high mountains, e.g. Mont Blanc, a guide points your attention to a cloud that steadily circles the mountain at an altitude of nearly $2500 \mathrm{~m}$ a.s.l. Condensation of cooled water vapor in the warm air flow rising along the mountain slope when they reach a temperature of a dew point is the reason for these cloud formations.

7) The peculiarities of the zones of infrared radiation, especially narrowing on the steep slopes, location on the surfaces of lakes, in coastal ocean or lake strips, 
and seasonal or diurnal dependence correspond to our assumption.

8) Large quantities of charged ions, e.g. Radon or Thoron gases, in the atmosphere along the tectonic brakes could intensify the process of vapor condensation.

9) With respect to the analysis of linear cloud anomalies (LCA) by Morozova [29], utilizing satellite imagery, the appearance of LCA above breaks in the lithosphere over various earth regions is a well-known natural phenomenon. LCA length can reach several hundreds of kilometers. A unified opinion concerning the nature of LCA is absent. Letnikov [30] asserts that lithosphere breaks are the sources of ionized radon which initiates the LCA formation. Other geologists support orographic factors of LCA appearance. In any case, the existence of LCA, as well as the seasonal and diurnal change of sources' intensities [17] supports our PeTa model.

It should be noted that, sometimes, together with endogen heat, the authors of the analyzed hypothesis suggest the heat of water vapor condensation as a possible infrared source: "Water vapor is transformed in a fog...The heat of the phase transition is liberated, the radiometers of satellites 'see' this heat" (our translation from Russian) [31]. This does not contradict our model in which only a part of the phase transition energy is emitted as the PeTa radiation. However, the heat of condensation seems not to be the only reason for the anomalies. Let us estimate this effect. If a reasonable quantity, $5 \mathrm{~g} / \mathrm{m}^{3}$, of water vapor during fog or cloud formation is condensed, and the energy of transition is completely thermalized and used only for air heating, it will increase the air temperature by $1 \mathrm{~K}$. In reality, this effect is recorded [31]: a systematic measurement of three weather stations in the above-mentioned Tunka Valley recorded a thermodynamical temperature on the mountain slope at the center of the thermal line that was $1^{\circ} \mathrm{C}$ higher than at the bottom of the valley.

Nonetheless, bright temperatures systematically measured by satellites in the same (Figure 7(a)) and other (Figure 7(b)) regions were $6-12 \mathrm{~K}$ higher. This fact can be explained if we assume that dew points coincide with the centers of thermal lines, and are located circa at the middle of mountain slopes. There cloud formation here is very intensive. A part of the liberated energy of phase transition is absorbed and heats the air and soil. It explains the thermodynamic temperature difference of $1 \mathrm{~K}$ between this place and the bottom of the valley. The other part of the liberated energy of phase transition is emitted as the PeTa radiation. It is added to Planck's radiation and increases the recorded bright temperature. Thus, the abnormalities of radiation temperature described above are a result of non-equilibrium PeTa radiation that is added to equilibrium Planck's radiation.

A fact that the authors of the above-analyzed paper [13] recorded infrared radiation in the range $8-14 \mu \mathrm{m}$ from the middle parts of mountain slopes also serves as an additional confirmation of our model.

PeTa energy could be stored. Let us imagine a system of two parallel mirrors (one of them is semitransparent) of area of $1 \mathrm{~m}^{2}$ on the distance of $1 \mathrm{~m}$ from 


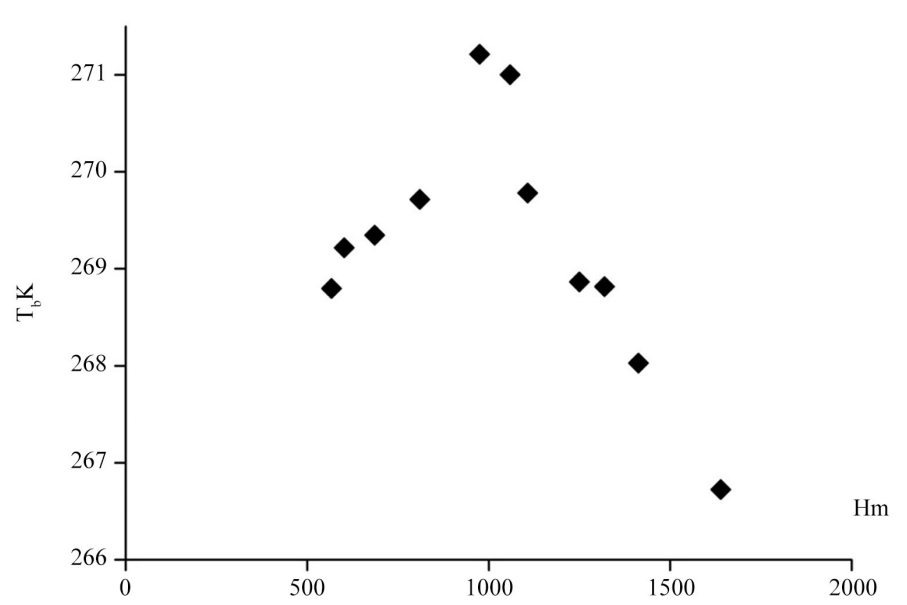

(a)

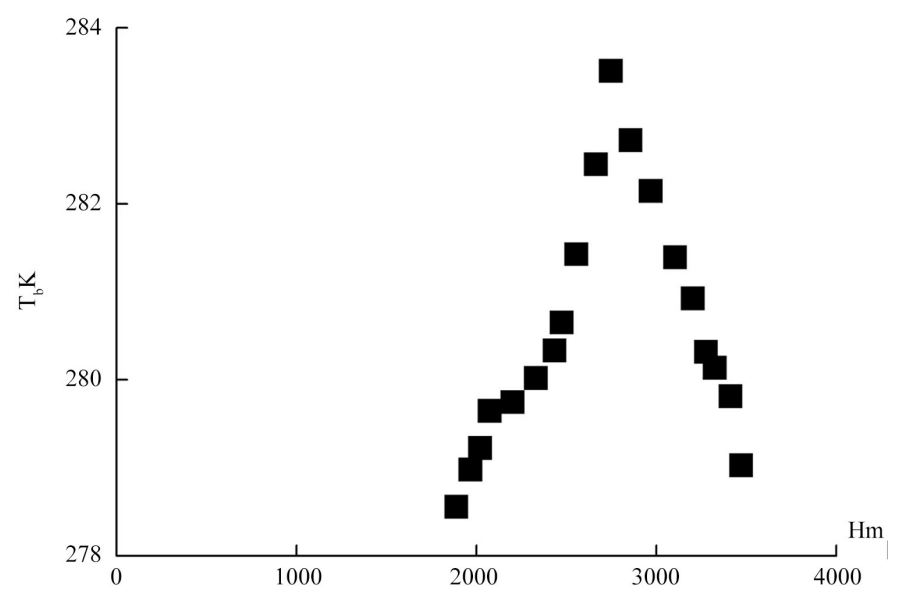

(b)

Figure 7. Distribution of bright temperature on the slopes of mountains: (a) from [23] Primorsky fault (Siberia, Russia); (b) from [26] Taibai west slope (California, USA).

each other. Let us locate this system in the atmosphere where the water vapor is saturating but is not condensed yet. Let us provoke condensing of the vapor. In this case about $5 \mathrm{~g}$ of water vapor will be condensed in our system. It means that $12 \mathrm{~kJ}$ of energy will be liberated. The system would work as a laser. For the $8 \%$ laser efficiency the energy of $1 \mathrm{~kJ}$ would be accumulated. A movement of the vapor with the speed $1 \mathrm{~m} / \mathrm{s}$ would provide a pulse generator of $1 \mathrm{~kW}$ power. For comparison, a silicon solar cell of $1 \mathrm{~m}^{2}$ area provides $100 \mathrm{~W}$ power.

\section{Condensation Explosions as Sources of PaTa Radiation}

\subsection{Registration of Powerful Pulses of IR Radiation in the Atmosphere}

Bordonsky [32] detected powerful pulses of infrared radiation in the atmosphere using a broadband radiometer in the wavelength range of $7-14 \mu \mathrm{m}$. First measurements were carried out in 1987 in Preobrazhenka village, Chita region (Russia), at an altitude of $1000 \mathrm{~m}$ a.s.l. A radiation pulse was registered at the time of 
the existence of weak thunderstorm clouds. By the way, in this area, there are unique weather conditions-at least 300 sunny days a year. The instrument had an angle of view of about $0.1 \mathrm{rad}$ and was oriented at an angle of $45^{\circ}$ to the horizon in the south direction. On July 14, the radiometer gave impetus of radiation of power exceeding all possible interference in the radiation pattern: birds, a sharp change in the cloudiness, etc. A storm was observed at a distance of few kilometers to the north. Calculations show that the observed signal could be a result of the lightning discharge in the distance of the order of $1 \mathrm{~km}$. However, in the fixing angle near the receiver's location, nobody did hear a thunderstorm. This however is not absolute evidence of absence in the field of the device of a lightning ball with poorly audible discharge. But if we consider that in August 1989, during a severe thunderstorm, the infrared radiometer did not register any pulses, while a set of microwave radiometers operating in the $18 \mathrm{~cm}$ range continuously recorded lightning strikes (about 100 lightning strikes were recorded), this excludes the possibility of false triggering of the radiometer in the previous case due to interference from low-frequency electromagnetic fields. Thus, there is an experimental fact: in July, the device recorded a radiation pulse, the magnitude of which exceeded all possible atmospheric noises. The recorded pulse corresponded to a radiation temperature of $340 \mathrm{~K}$ with a background temperature of $260 \mathrm{~K}$ (Figure 8).

This experimental fact is not the only one: in the same place, on December 14, 2006, a similar emission was recorded [33]. The members of this research group did not exclude the PeTa nature of the radiation recorded in their experiments [34] but this does not answer the question about the sources of this radiation.

\subsection{Flash Implosion Craters in Balloon Date}

At first glance, such powerful flashes of PeTa radiation in a weakly cloudy sky are amazing. However, it turns out that the appearance of these outbursts is quite understandable. J. Jenkins in his website [35] describes such an interesting phenomenon as condensation explosions in the earth's atmosphere, arising for the following reason: temperature in the troposphere decreases with height. Even in good weather, under conditions of light cloud cover and weak wind, significant volumes of supersaturated vapor arise in certain places of the atmosphere during the convective rise of warm air. When the critical supersaturation

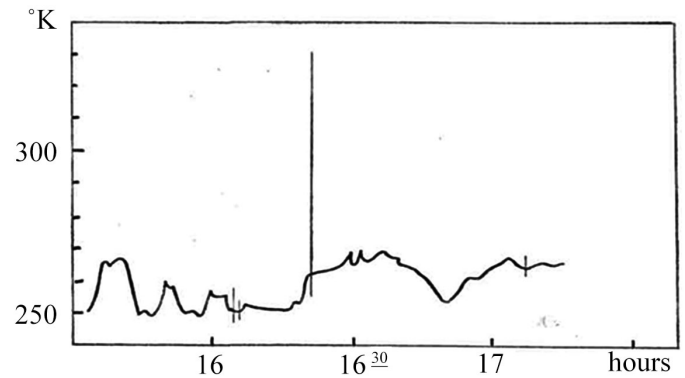

Figure 8. From [32]. Infrared pulse: Radiation temperature $(\mathrm{K})$ versus local time (Hours). 
of steam is reached in such a volume, instant condensation occurs-a condensation explosion. It should be noted that the phenomenon of condensation explosions by its physical nature belongs to the same category of physical phenomena as the glow of bubbles during cavitation luminescence (CL), sonoluminescence (SL), luminescence of laser-induced bubbles (LIBL), and luminescence of vapor bubbles (VBL) [8] [9] [10]. Similar to the listed effects, it is very convenient to represent the phenomenon of condensation explosions on the nonequilibrium phase diagram of water vapor-water-ice [10] [11].

It is very likely that the IR pulses detected in [32] [33] are the result of such condensation explosions emitting PeTa radiation. After condensation explosions, craters remain in the atmosphere, which are characterized by a sharp difference in temperature, pressure, and humidity from the surrounding atmosphere. Jumps in temperature and wind rotation are recorded by research probes passing through funnels left by condensation explosions. A huge number of records show that there are many such craters in the ordinary sky, i.e. infrared flashes caused by condensation emissions occur continuously during normal weather. Craters exist for a long time and then dissolve. Temperature jumps last the longest.

Let us consider examples of this phenomenon on the basis of the site [35], which presents many research results that record the presence of condensation craters: 15 soundings of the atmosphere from Norfolk Island, 34 from New Caledonia, and 15 from Fiji. For Jenkins, studying normal weather is much more important to understanding climate than studying storms and unusual weather. The most common weather on Earth is a clear sky over the ocean with a constant wind. We present 1 graph (Figure 9) from [35], which represents some atmospheric parameters in normal weather at the Norfolk Island weather station. According to [35], similar atmospheric sounding data for the entire territory of North America are available at (http://weather.uwyo.edu/upperair/sounding.html).

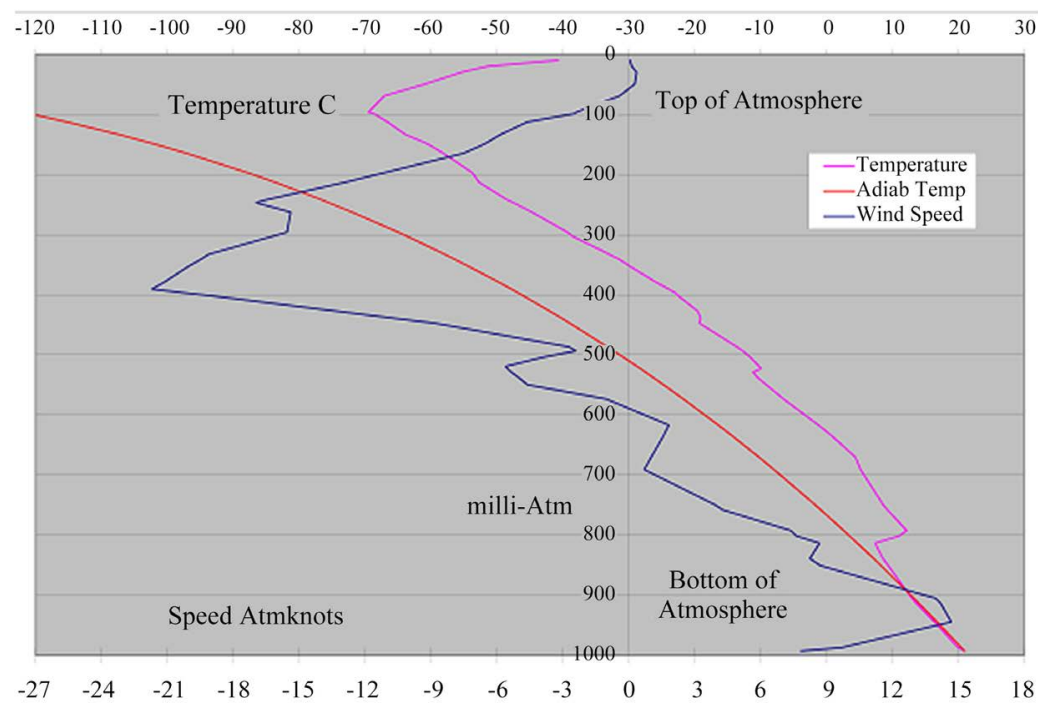

Figure 9. From [35]. Some atmospheric parameters obtained with a weather balloon during normal weather at the Norfolk Island weather station. 
Upward movement of air is adiabatic expansion, and downward movement of air is adiabatic compression. Expansion makes the air colder, and contraction returns its temperature to the surface temperature. The graph shows that the recorded temperature drop with height is much less than it would be for a purely adiabatic process.

In the graph presented, the wind speed is $\sim 15$ knots at the surface and $\sim 30$ knots with a turn in almost the opposite direction at an altitude of $\sim 1000$ meters a.s.l. In combination with lower pressure at this altitude, the power of the air flow, and, therefore, its continuity is maintained. This change in the magnitude and direction of the wind in the near-surface layer of the atmosphere is associated with a sharp change in the friction force with height and is represented by the Ekman spiral. A change in wind direction at an altitude corresponding to a pressure of $\sim 400$ milliatmospheres is not accompanied by a change in temperature and is the result of some global processes in the atmosphere. We are interested in three intermediate changes in wind speed and direction, which correspond to temperature jumps. It is there that the balloon passes through the craters left by the explosion of condensate.

An overwhelming number of records show that the normal sky is full of such craters. Condensate explosions have led to bursts of infrared radiation, so the craters show that bursts of radiation occur constantly in normal weather. It follows from the graph that condensation explosions in a specific place are not a frequent phenomenon; therefore, it is natural that only individual radiation pulses were recorded experimentally.

It should be remembered that the explosions that caused the craters occurred before the balloon got there. Each crater dissipates heat, so its power, when the balloon arrives, is not the same as it was when it happened. Explosions cause rotation. Rotation accelerates the wind toward the surface below the center of the crater and reduces speed in that direction or even changes its direction above the center of the crater. The wind caused by the crater disappears first. The jump in humidity can also disappear, but the jump in temperature remains the longest.

\subsection{Laboratory Experiments}

In laboratory facilities, for about 20 years, a group of researchers from Lithuania has been experimentally researching the condensation implosions phenomena that can occur for horizontally stratified liquid-vapor flow conditions [36] [37] [38] [39] [40]. The goal is to understand the critical boundary conditions sufficiently so that the phenomenon can be controlled and initiated at will.

Diagram of the experimental setup used in [36] [37] [38], is shown in Figure 10. The installation operates as follows. Steam is generated in boiler 4 and stored in tank 5 , from where it is sent to research chamber 1 and is contained therein at the required pressure. Then from vessel 2 into the research chamber 1, which begins to supply water at a fixed rate through dispenser 3 from the bottom. As water is supplied, due to the shape of research chamber 1 (horizontal cylinder), the area of contact between water and steam increases. The rate of this increase 
depends on the rate of water supply. When the water surface area reaches a certain critical value, a condensation explosion occurs, which is recorded by a sharp drop in pressure in chamber 1 due to instantaneous condensation of steam, Figure 11.

For us in these experiments, it is essential, first, to prove the existence of condensation explosions; secondly, the realization of condensation explosions when a certain critical value is reached by the area of contact between steam and water.

In further work, the group developed a thermal-hydraulic system in which periodic condensation flashes are the driving force of water circulation [39] [40]. The advantage of the system is that its operation does not require a pump to maintain circulation. Such a system does not require an external source of energy and could be used, for example, for emergency cooling of a nuclear reactor in the event of a power failure and stopping the main circulation pump.

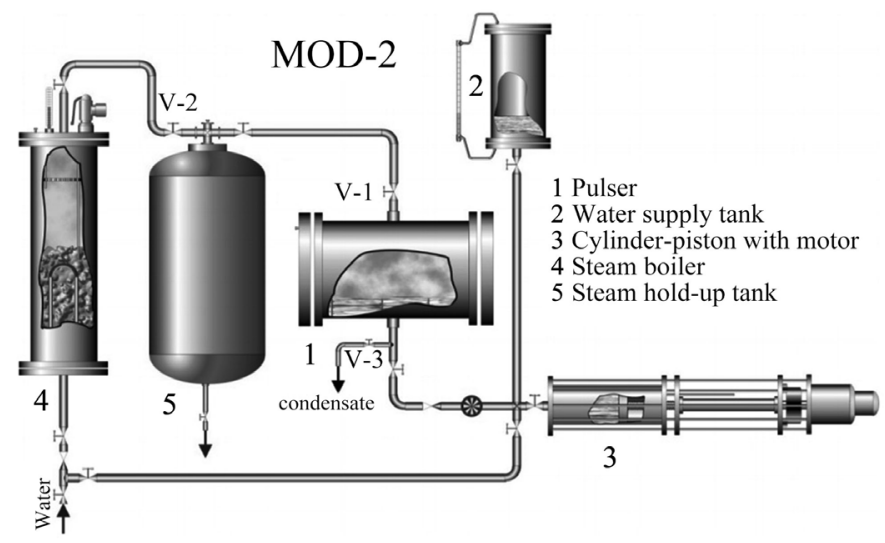

Figure 10. From [35] MOD2 Pulser Test Facility: 1, pulser; 2, water supply tank; 3 , cylinder-piston with motor; 4 , steam boiler; 5 , steam hold-up tank; 6,9 , thermocouples; 7 , pressure transducers; 8 , flow meter; 10 , data acquisition system.

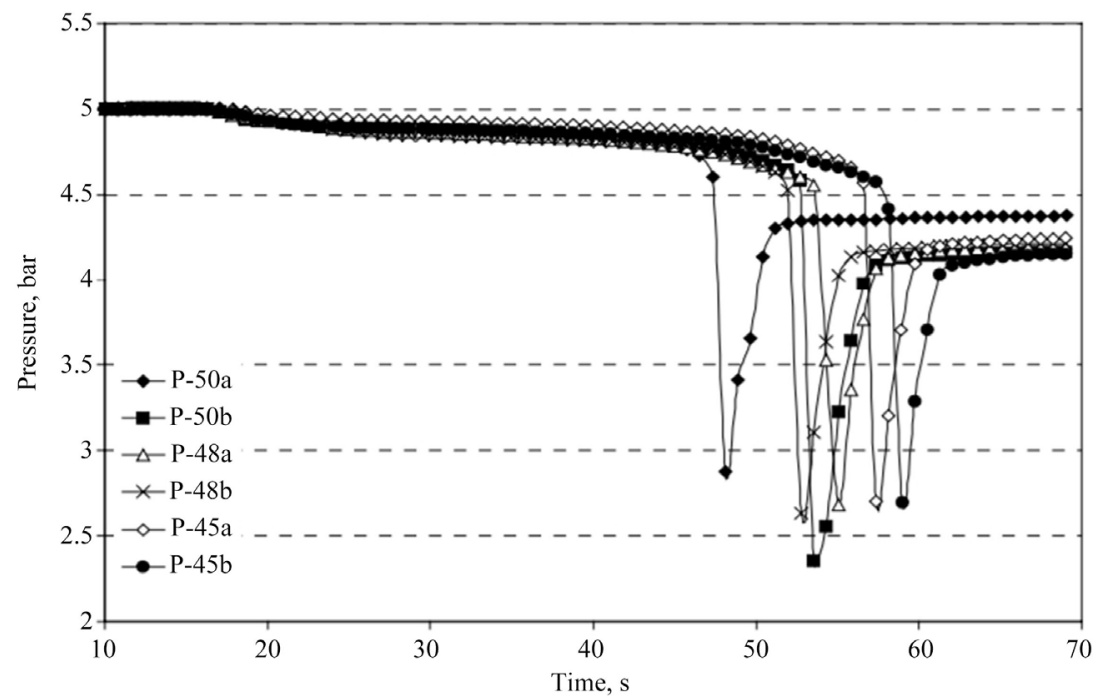

Figure 11. From [35] Pressure change $\mathrm{P}(\mathrm{t})$ for varying liquid flow rates. Open steam line; water nozzle diameter $1 \mathrm{~cm} ; 50,48,45-$ voltage supplied to the plunger motor; a, b-experimental test. 
Based on this modeling and experiments, it can be assumed that in nature, condensation explosions can occur not only in the high-altitude layers of the atmosphere but also in moving fog over the water surface, if the wind speed is 4 $6 \mathrm{~m} / \mathrm{s}$, as a result of which the water surface is disturbed.

\section{Measurements of the Concentration of Water Vapor in the Atmosphere}

As a rule, 6.7 - $6.9 \mu \mathrm{m}$ IR radiation of the Earth has been particularly useful for recording water vapor in the Earth's atmosphere. Presently, a lot of infrared images of the Earth taken from the Space in this range exist. For instance, [41] confirm that the NASA orbiting GOES 8 satellite's multi-channel imager produces images of the upper troposphere at the infrared wavelength of $6.7 \mu \mathrm{m}$ (Figure 12). Another example is the images obtained by the Japanese weather satellites of series GMS 5-GMS 9. According to [42], for the water vapor images on the GMS satellites, the radiometers VISSR with a range of measurement 6.5 - $7.0 \mu \mathrm{m}$ have been installed. But do modern meteorologists understand why this particular range is used to measure water vapor concentrations? The book of [43] is usually used for the interpretation of images. There we read: "Water vapor imagery is derived from radiation emitted by water vapor at wavelengths around $6.5-7.0$ $\mu \mathrm{m}$. This is not an atmospheric window but a part of the spectrum where water vapor is the dominant absorbing gas. The center of the absorbing band is $6.7 \mu \mathrm{m}$. Emissions from water vapor low in the atmosphere will not normally escape to space. If the upper troposphere is moist, the radiation reaching the satellite will mostly originate from this (cold) region and be displayed in white shades, following the IR imagery color convention. Only if the upper atmosphere is dry, radiation will originate from water vapor at warmer, mid-tropospheric levels and be displayed in darker shades on the image. In a normally moist atmosphere, most of the IR radiation received by satellite originates in the $300-600$ $\mathrm{hPa}$ layer, but when the air is dry some radiation may come from layers as low as $800 \mathrm{hPa}$. Because of the general poleward decrease of water vapor content, the height of the contributing layer gets lower toward the poles". The authors seem to propose a reasonable scheme of the image interpretations on the basis of radiation emitted by water vapor with the center of the band located at $6.7 \mu \mathrm{m}$. It is only surprising: why up to now, nobody has been interested in the physical nature of this radiation while, no doubt, this is the PeTa emission? Thus, there are a lot of misunderstandings without a clear physical interpretation of this phenomenon. For instance, the site (Imaging the Earth) describes Figure 12: "The imager on this satellite records radiation emitted by water vapor in the upper troposphere. Regions with high concentrations of water vapor are bright, while dark spots signal lower water vapor concentrations." On the other hand, for the same image, on the site (http://antwrp.gsfc.nasa.gov/apod/ap020323.html), there is the following description: "These instruments can produce images at the infrared wavelength of 6.7 microns, recording radiation absorbed by water vapor 


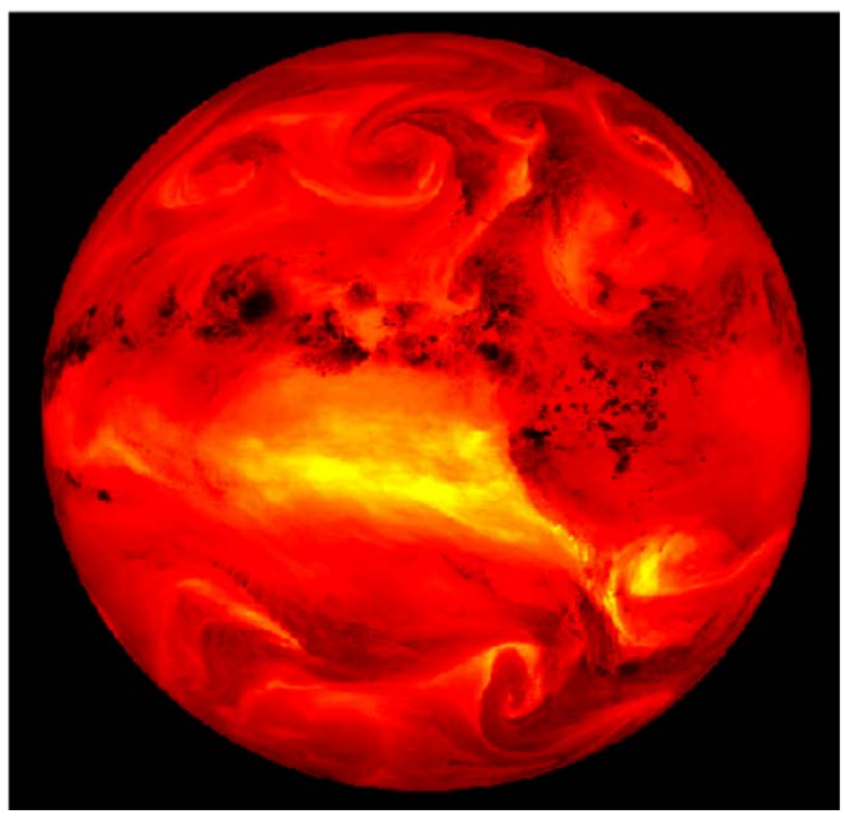

Figure 12. From [41]. Earth image at the infrared wavelength of $6.7 \mu \mathrm{m}$, recording radiation emitted by water vapor in the upper troposphere.

in the upper troposphere. In this picture, the planet's dark regions correspond to high concentrations of water vapor over storms and high cloud tops, while bright areas are relatively dry." No comments.

For a set of TIROS (Television and Infra-Red Observation Satellites), the system TOVS (TIROS Operational Vertical Sounder) was developed. With respect to the paper [44], it was also installed on board the NOAA series (National Oceanic and Atmospheric Administration) of polar-orbiting satellites. The system TOVS contains three water vapor channels located at 6.7, 7.3, and 8.3 $\mu \mathrm{m}$. The channels are sensitive to relative humidity in the upper, middle, and lower troposphere, respectively. Thus, there is an empiric experimental fact. But what is the physical nature of these sensitivities and, hence, why were these ranges chosen? The authors explain: "Satellite observations of the upwelling infrared radiation in the $6.3-\mu \mathrm{m}$ water absorption band provide a unique source of information on tropospheric water vapor." If this postulate is accepted, then two questions arise: 1) Why are ranges rather far from $6.3 \mu \mathrm{m}$ ? 2) Why are they essentially different for three altitudes? Let us analyze this problem. The keywords to be dealt with are "relative humidity" and "three vapor channels...sensitive...in the upper, middle and lower troposphere". First of all, the device is sensitive to the relative humidity (i.e. to the energy of vapor condensation and/or deposition) but not to the absolute one. Secondly, different energies recorded from the three tropospheric levels correspond to three various combinations of temperatures and pressures. Hence, both discrepancies could be completely explained in the frame of our PeTa model. It is important to bear in mind that PeTa power is proportional to the speed of cloud formation (i.e. to the speed of condensation and/or deposition) but not to the cloudiness. This is the 
reason why we are not surprised to read in the paper under consideration that TOVS's data do not correspond to the radiosonde's ones. Most likely two devices measure different physical atmospheric characteristics (presumably relative and absolute humidity).

It is interesting to compare the two methods of measuring the humidity of the atmosphere: emitting of infrared radiation and absorption of highfrequency radiation. The second method is based on the experimental fact of emission of electromagnetic radiation from the earth's surface in a wide range of wavelengths. Water vapor and oxygen have multiple absorption bands in the spectrum (Figure 13) [45]. As a rule, the strongest absorption band of $1.35 \mathrm{~cm}(f=\sim 22.2 \mathrm{GHz})$ is used to determine the amount of water vapor in the atmosphere.

If the measurement is made from a satellite in a direction perpendicular to the earth's surface, the total content of water vapor in the atmosphere can be measured. In the paper [46], the author notes the presence of own infrared radiation in the atmosphere, unfortunately, without discussing the physical nature of this radiation; a comparison is made between two methods for measuring humidity-infrared and microwave (Table 2). Besides, a combination of both methods is possible-the addition of an infrared radiometric channel of the $7-10 \mu \mathrm{m}$ or $7-14 \mu \mathrm{m}$ range to the microwave measuring system opens up the possibility of measuring humidity at low water vapor content. The choice of these infrared ranges for measurement seems to be empirical again without understanding the physical nature of this radiation.

Table 2. Comparison between three methods for measuring humidity-infrared, microwave and combined.

\begin{tabular}{|c|c|c|c|}
\hline & Infrared & Microwave & Combined IR and microwave method \\
\hline \multirow{3}{*}{ Advantages } & High level of self-radiation of the atmosphere & $\begin{array}{l}\text { Aerosol does not affect the } \\
\text { measurement results }\end{array}$ & $\begin{array}{l}\text { Possibility to eliminate the influence of the } \\
\text { aerosol }\end{array}$ \\
\hline & $\begin{array}{l}\text { Extensive use of different wavelengths for } \\
\text { the hardware adaptation of the season }\end{array}$ & $\begin{array}{l}\text { The range weather conditions: } \\
\text { summer, spring, autumn. }\end{array}$ & $\begin{array}{l}\text { Advanced application range complex weather } \\
\text { conditions and seasons. }\end{array}$ \\
\hline & $\begin{array}{l}\text { Due to the optics you can create a compact } \\
\text { and highly directional gauges } \\
\text { It opens the possibility of estimating the } \\
\text { height of cloud and moisture in-cloud layer }\end{array}$ & $\begin{array}{l}\text { Clouds without precipitation } \\
\text { can be measured }\end{array}$ & $\begin{array}{l}\text { Possibility of obtaining further information } \\
\text { on the lower boundary of clouds and thick } \\
\text { clouds using infrared measurements for } \\
\text { microwave tomography method }\end{array}$ \\
\hline \multirow{3}{*}{ Disadvantages } & $\begin{array}{l}\text { Method are influenced by aerosol, which is } \\
\text { difficult to prediction }\end{array}$ & $\begin{array}{l}\text { Method is intended for use in the } \\
\text { summer. In winter, its use is } \\
\text { extremely limited }\end{array}$ & $\begin{array}{l}\text { Complicated measuring equipment and data } \\
\text { processing. }\end{array}$ \\
\hline & $\begin{array}{l}\text { Influenced by cloud cover, which entails } \\
\text { limiting the height sensing and difficulties } \\
\text { in processing the results of measurements } \\
\text { in-cloud layer }\end{array}$ & $\begin{array}{l}\text { Clouds and precipitation require } \\
\text { the use of additional wavelengths } \\
\text { to account for their influence. }\end{array}$ & The increase in the price of the complex \\
\hline & $\begin{array}{l}\text { The complexity of the calibration at } \\
\text { a low level of atmospheric radiation }\end{array}$ & $\begin{array}{l}\text { Highly sensitive } \\
\text { equipment is needed }\end{array}$ & \\
\hline
\end{tabular}




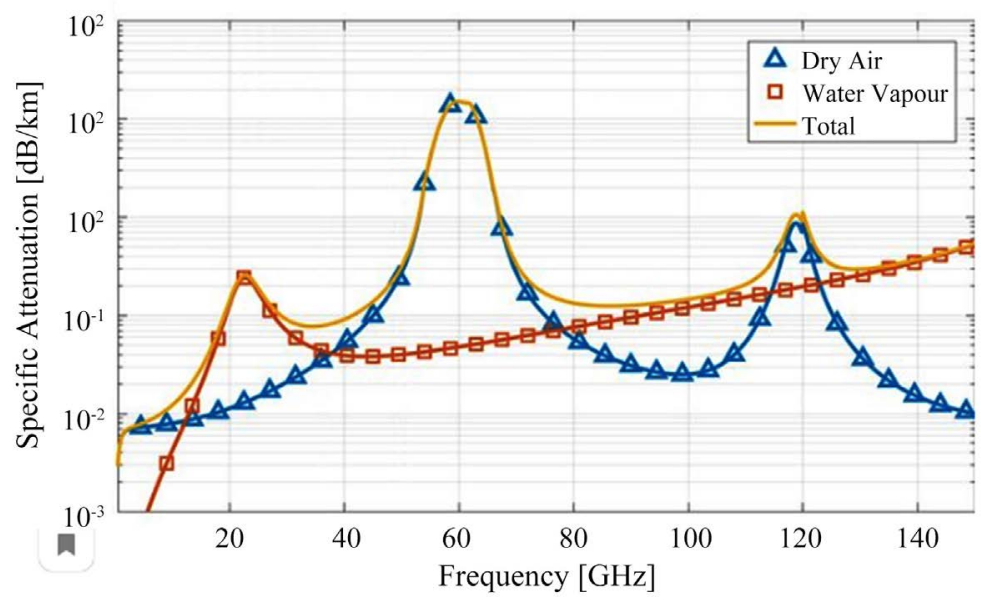

Figure 13. From [45] Atmospheric absorption due to water vapor and gases in the millimeter-wave spectrum.

\section{Atmospheric Scintillations and the PeTa Effect}

Scintillation is a general term for rapid changes in the apparent position, brightness, or color of a distant luminous object observed in the atmosphere. In the visible region, scintillations are associated with the scattering of light by fluctuations in the density of air and microscopic drops or particles in air. According to the Rayleigh law, the scattering intensity is $\mathrm{I} \sim 1 / \lambda^{4}$ ( $\lambda$ is the wavelength of light). Therefore, in diffused sunlight, blue and violet colors prevail, which explains the color of the sky. But we do not see scintillations of the colors of the sky, because fluctuations of air density in relatively small volumes are sufficient for the scattering of blue color, and this happens with a high probability. Photons with a longer wavelength in the visible and infrared ranges require the formation of larger fluctuations, which is less likely, therefore, scintillations of this radiation are also less likely. This statement is beyond doubt. At the same time, experiments show that atmospheric scintillations in the visible and infrared ranges are likely to have a different nature. Let us analyze the features of this phenomenon in the infrared range.

In the paper [47], the observation is described that scintillation intensities measured with LOPAIR (Long-Path Infrared operating near $10 \mu \mathrm{m}$ ) equipment in the desert near Yuma, Arizona, were much bigger than those observed at Edgewood Arsenal, Maryland, under similar seasonal conditions. LOPAIR is a device designed to measure the concentration of harmful gases in the atmosphere by absorbing certain radiation in the infrared range. For these experiments, the device was suitably modified. In both cases, the distance between the radiation source and the receiver was 400 meters. The effects of haze and particles were ruled out since heavy scintillation frequently follows heavy rain when the air is washed clean. From experiments, it follows that in the IR range, scintillation only occurs at high relative humidity. Thus, only humidity, dissolved gases, and suspended particles could seem to account for the apparent discrepancy. What is the difference between natural conditions in these two geographical points? At 
Yuma, the difference between the air temperature near the ground and the air temperature along the line of sight is enormous. It is not inconceivable that water vapor, which on the macroscale dominates weather patterns, producing clouds and precipitation, might contribute to a microphenomenon such as terrestrial scintillation. A range $\sim 10 \mu \mathrm{m}$ and the place (desert) correspond to the PeTa emission registration in Figure 2(a), Figure 2(b). It is therefore natural to assume that it is linked to the PeTa radiation during the formation of microscopic droplets in the atmosphere. This means that the physical nature of scintillations in the infrared region is the same as the nature of abnormal continuous absorption.

Indeed, air heated at the surface of the earth constantly rises, while being intensively cooled. Upon reaching the dew point in these air flows, condensation of water vapor begins with the emission of PeTa radiation. In parallel with this process, another is inevitable-streams of cold air moving toward the earth are formed. The presence of these oncoming flows leads to inevitable turbulence, and, consequently, to the uncontrolled appearance of regions with a temperature corresponding to the temperature of the dew point. Thus, the chaotic appearance of PeTa radiation sources occurs. Recall that a similar chaotic PeTa radiation is described in [6]. It occurred when hot steam, stirred by a fan, was admitted into a cold chamber with a volume of $21 \mathrm{~m}^{3}$.

Of course, we cannot exclude the possibility that, along with PeTa radiation, a certain contribution to the scintillation of IR radiation is made by the absorption and scattering of radiation by microscopic drops of water formed as a result of condensation.

\section{PeTa Radiation and Living Organisms}

In nature, PeTa radiation has a rather strong direct effect on humans and animals.

\subsection{PeTa Radiation and Igloo Effect}

An igloo, or a snow house, is a type of shelter built from the snow. On the outside, temperatures may be as low as $-45^{\circ} \mathrm{C}$, but on the inside, the temperature may range from $-7^{\circ} \mathrm{C}$ to $16^{\circ} \mathrm{C}$.

These buildings are widespread among the peoples of the north because they provide comfortable living conditions for their inhabitants (Figure 14). Moreover, based on the principles of an igloo, comfortable hotels are currently being built (Figure 15). The most amazing thing is that the colder the outside the warmer inside. What is the reason for this?

The authors of the paper [48] tried to answer this question by modeling thermal conditions in an igloo. They used the mathematical program FIDAP with the geometry and boundary conditions shown in Figure 16. The conclusion of the authors is as follows: Elevated temperature in igloos is explained by the fact that snow is a good insulator and the human body is a source of heat. 
It should be noted that the author of this paper has a special relationship with the FIDAP program. In 1993, I was engaged in the development of the technology of growing sapphire crystals [49]. Sapphire has a melting temperature of $2050^{\circ} \mathrm{C}$. I grew the crystals from molybdenum crucibles. Molybdenum has a melting point of $2800^{\circ} \mathrm{C}$. In one experiment, a colleague of mine proposed that I should calculate the conditions for crystal growth using the FIDAP program. As a result, it was a single experiment in my life in which the crucible melted. The fact is that the FIDAP takes into account only convective (nonradiative) heat exchange. No comments.

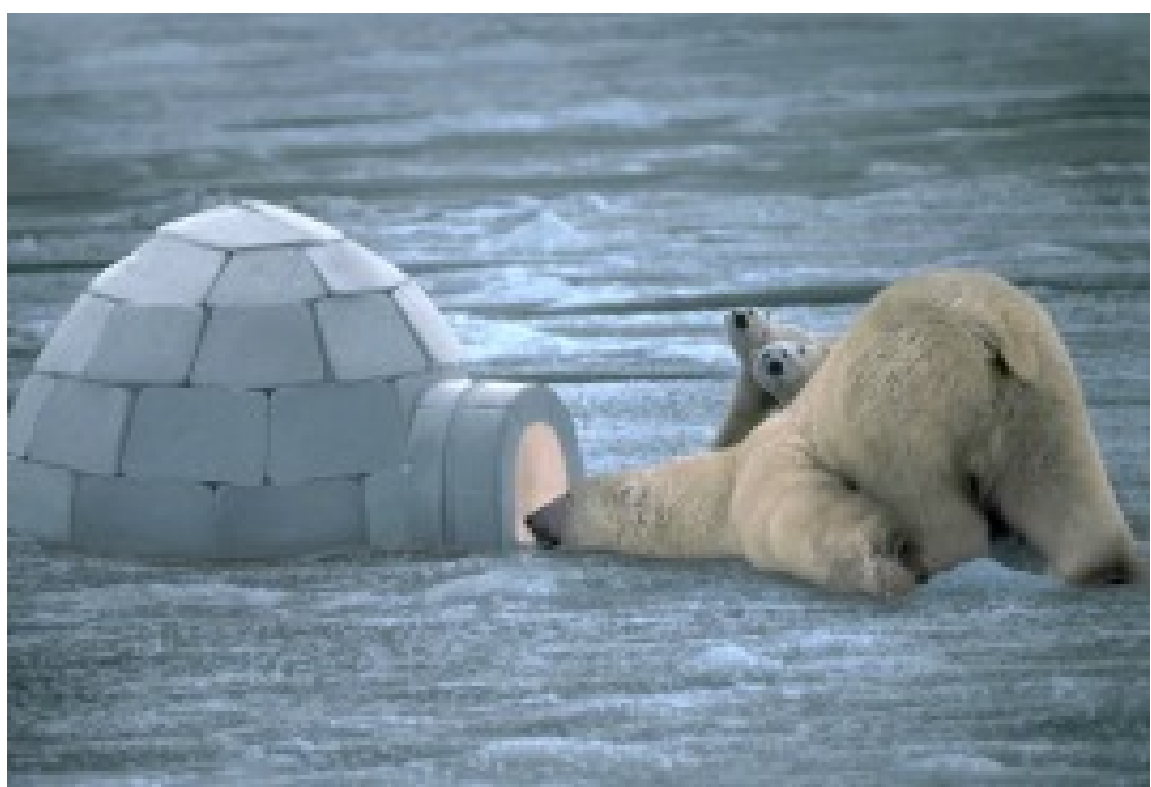

Figure 14. From:

(http://vamvigvam.ru/blog/2015-05-10/iglu-traditcionnoe-zhilische-skimosov); Classic igloo.

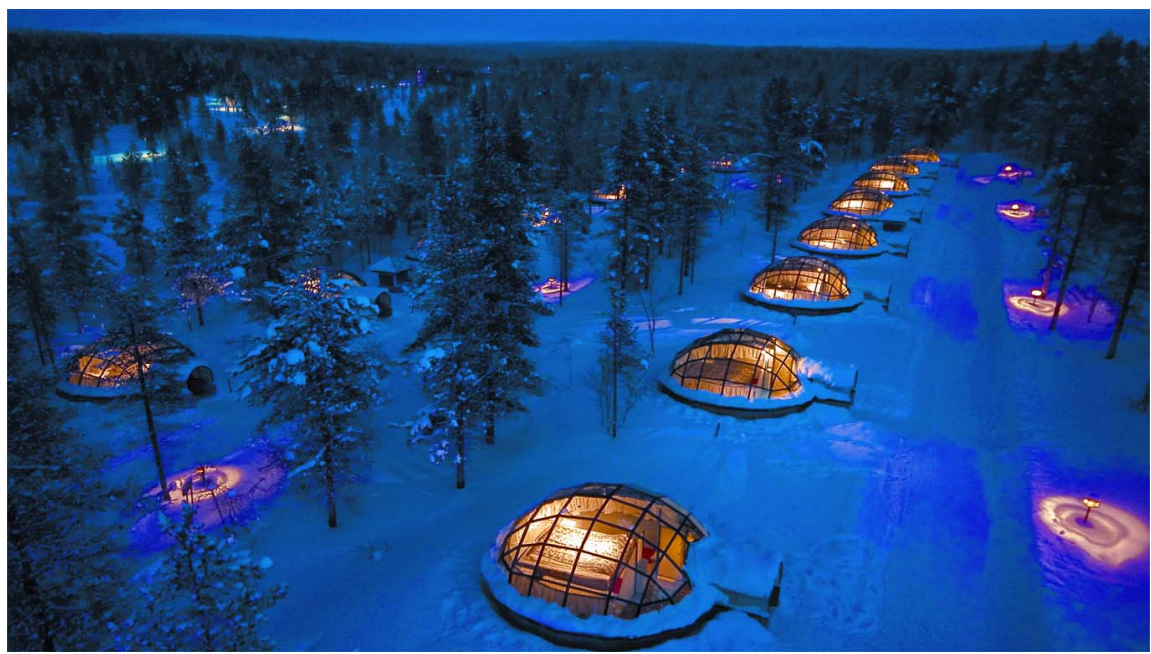

Figure 15. Kakslauttanen Arctic Resort-Igloos and Chalets, from (http://images.google.fr/imgres?imgurl=http://www.kakslauttanen.fi/assets/2013/09/) Igloo-hotel. 


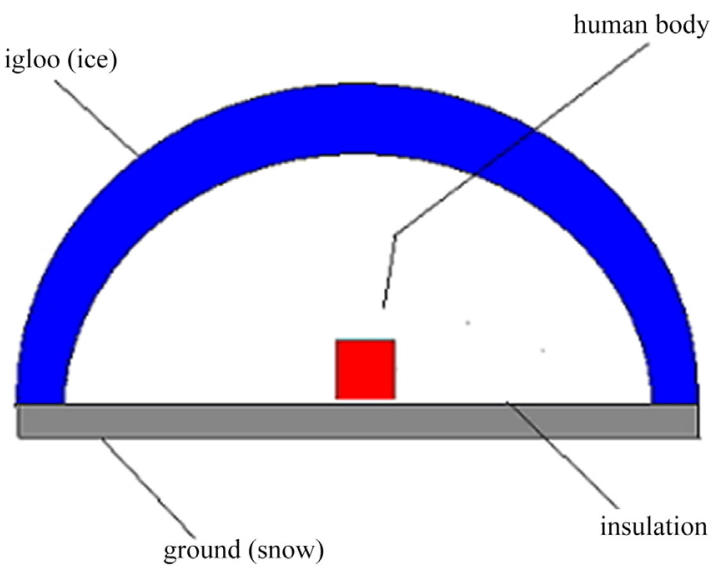

side view

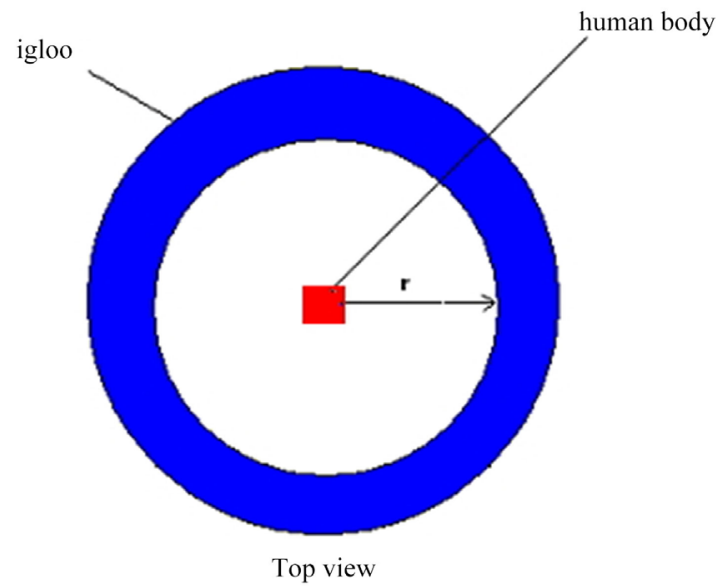

Figure 16. From [48]. Igloo geometry.

But now, let's get back to the subject at hand. Obviously, the authors of the paper [48] did not explain why the inside of the igloo becomes more comfortable when it is colder on the outside. The main reason is that it is impossible to take into account only conductive heat transfer and ignore the radiative one. Indeed: firstly, now luxury ice hotels are widespread with ice sculptures inside; it means that the temperature inside these hotels could not be positive. Secondly, the hotels with thin glass walls are numerous (Figure 15). In this case, the walls of the igloo have the temperature of the outside air. As doctors say, the peculiarity of the situation lies in the fact that the person feels comfortable, even at temperatures below freezing point, if his body heats up a source of infrared radiation. A good confirmation of this is, for example, bare-chested skiers on a mountainside at low temperatures but in the sun. Our experiments of [6] [7] indicate that the walls of the igloo from snow or glass have to be a good source of the PeTa radiation. Recall that a wall cooled to $-25^{\circ} \mathrm{C}$ emits $\mathrm{PeTa}$ radiation, the integral intensity of which is equal to the Planck radiation of a wall having a temperature of $+25^{\circ} \mathrm{C}$. A significant part of this radiation is located in the window of air transparency. It had not been absorbed with the air in the igloo, and thus, does not 
heat the air inside. On the other hand, the radiation is absorbed by the human body, and heats him. Most likely, this is the reason the wide use of these habitations in northern areas. From our point of view, a good experiment would be to place a model of a human figure inside an igloo and measure the temperature of its surface and heat flux at different values of the external and internal temperatures.

There is another interesting circumstance: the authors of the paper [50], who are engaged in research of Vernacular Architecture, are interested in our explanation of the effect of the igloo. Vernacular architecture means an architectural direction that uses thousands of years of experience in building structures that take into account and practically apply the geographic and climatic features of a particular area. We are confident that, taking into account our explanation, the igloo effect can be widely used in the construction of structures in the Arctic and Antarctic climatic zones.

\subsection{Stuffiness before Thunderstorm and Real (Feel) Temperature}

The stuffiness before a thunderstorm is a well-known effect that ceases with the first droplets of rain. See for instance

(http://www.youtube.com/watch?v=HEL9jm4jZoI): It was a very stuffy day and suddenly there comes a very short but heavy thunderstorm! Most likely, the effect is a result of PeTa radiation during intensive thunderstorm cloud formation. But the influence of clouds on the feeling of people is not limited to the closeness of thunderstorms. It is obvious that the cloud protects the earth's surface from direct sunlight (Shortwave radiation). At the same time, during its formation, the cloud emits the PeTa infrared radiation. A substantial portion of it lies at the atmospheric transparency window. It is not absorbed by the air and thus does not increase its temperature. But it is absorbed by the human body. Therefore, during the formation of clouds, it appears as if the temperature a person feels was raised. This effect is similar to that which holds in the igloo and is described in point 7.1.

At present, several weather sites show not only the measured (thermodynamical) temperature but also a real (feel) temperature, e.g.

(http://www.accuweather.com/fr/fr/paris/623/hourly-weather-forecast/623). For this, the AccuWeather RealFeel Temperature, e.g.

(http://www.accuweather.com/en/weather-news/what-is-accuweather-realfeel/7 198202), was developed in the 1990s. The RealFeel Temperature is calculated from an equation that takes into account multiple factors to determine how hot or cold feels. Some of the components that are used in the equation are humidity, cloud cover, winds, sun intensity, and the angle of the sun. Humidity is a large contributor to determining the RealFeel, but the time of the day also is important, due to the angle of the sun.

But we have our vision of the problem: if there is a cloudy day or fog formation, the real (feel) temperature has to be higher than the thermodynamic one because of PeTa radiation during the cloud or fog formation. It would be interesting to know that to determine the RealFee temperature, the PeTa radiation is 
included among a number of parameters. For this, methods of the PeTa radiation measurement should be developed. As a second step, dependence has to be found between PeTa radiation intensity and relative humidity, as well as the rate of formation of clouds or fog.

\section{PeTa Effect in Connection with Tropical Storm Characteristics}

Three types of tropical storms are commonly found in the literature: hurricanes, cyclones, and typhoons. They are all the same weather phenomena, but different names for these storms in different places are used. In the Atlantic and Northeast Pacific, the term "hurricane" is used. The same type of disturbance in the Northwest Pacific is called a "typhoon", while "cyclones" occur in the South Pacific and Indian Ocean. The concept of the energy mechanism for the development of tropical cyclones is widely known. In accordance with this concept, the main source of cyclone energy is the release of the heat of condensation of vapor in powerful convective clouds ("hot towers") in the atmospheric boundary layer. Since the 60s of the last century, this concept has been the basis of many theoretical works on the analysis of the conditions for the development of tropical perturbations of various spatial and temporal scales [51] [52]. For the formation of a cyclone, a reserve of potential energy is required, which can relatively quickly transform into kinetic energy of the wind at an extreme speed. This potential energy accumulates in the atmosphere over the ocean in the form of vapor gradually, until the formation of a cyclone.

To us, this concept seems to be quite reasonable, while PeTa radiation, apparently, can provide an additional assessment of the characteristics of tropical storms. A background of our idea is evident: when a cyclone forms, a large amount of water vapor condenses, turning into "torrential rains". This releases tremendous energy that heats up the surrounding air. Part of this energy is released in the form of PeTa radiation. It is necessary to learn how to evaluate this energy and thus judge the energy processes in a hurricane.

In practice, the lack of direct measurements of tropical storm intensity in the field has stimulated the development of intensity estimation methods based on satellite imagery. The very first technique to estimate the intensity of tropical storms was developed by V. Dvorak [53]. In this technique, an analyst classifies the cloud scene types in visible and infrared satellite imagery and applies a set of rules to calculate the intensity estimate. The technique is still used in many tropical storm forecasting centers around the world.

Some changes are sometimes used. For example, the article [54] introduced the temperature difference between 1) the warmest pixel temperature near the eye of a tropical cyclone; and 2) the coldest of the warmest pixel temperatures found on concentric rings around the center. This temperature difference is used as the main quantitative characteristic of the cyclone power. The modification is known as the Dvorak objective technique. This takes into account the 
intensity of infrared radiation (10.7 - $12 \mu \mathrm{m})$, on the basis of which the radiation temperature is calculated [55] (Figure 17(a), Figure 17(b)).

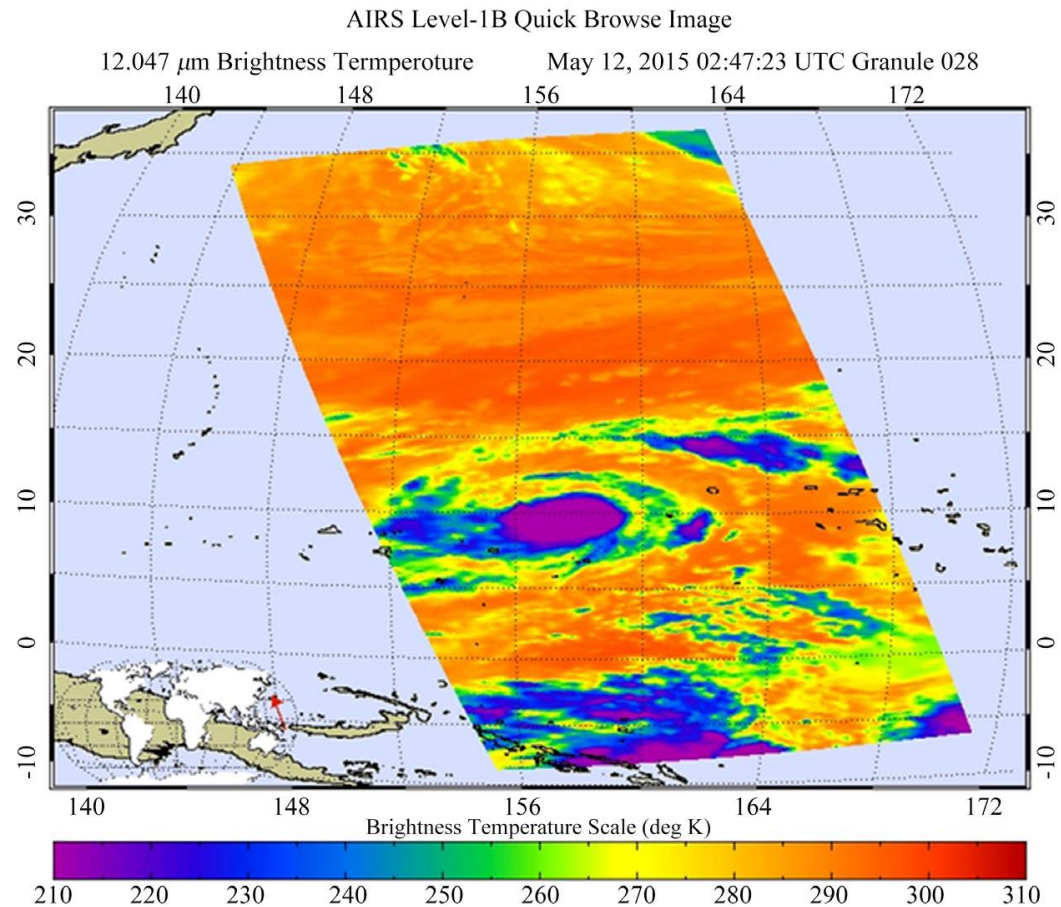

(a)

AIRS Level-1B Quick Browse Image

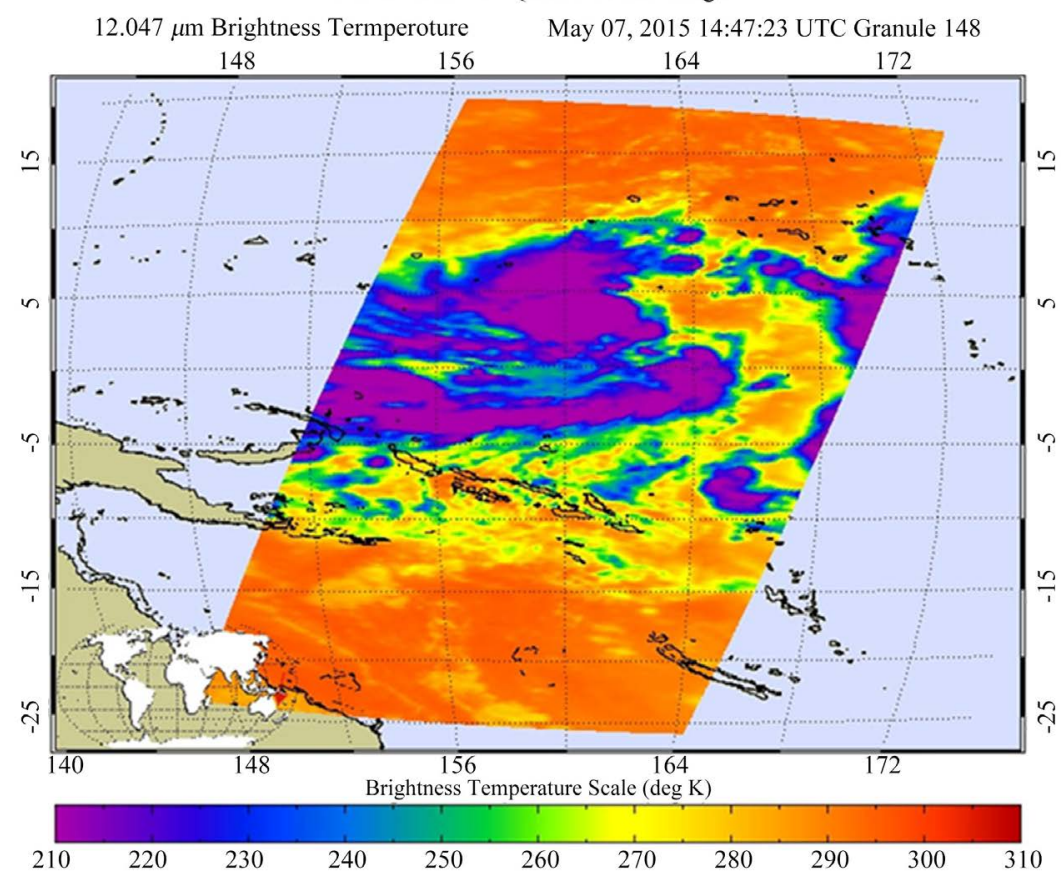

(a)

Figure 17. Two images of the radiation intensity of Typhoon Dolphin, received on May 12, 2015 using the AIRS instrument image radiometer at a wavelength of $12.047 \mu \mathrm{m}$. Using a standard technique, the spectral radiation power is converted to radiation temperature. 
Maybe these techniques are enough and there is no need to change anything? Let's try to figure it out.

In fact, the radiation temperature used in all these schemes, calculated on the basis of the power of infrared radiation, is a certain value equal to the sum of the Planck temperature radiation and PeTa radiation, the intensity of which is proportional to the rate of condensation of water vapor. In this case, the Planck temperature characterizes the energy that is actually present in the cloud, and PeTa radiation - the energy that is carried away from the cyclone zone into space. The sum of these values has no physical meaning. Indeed, the difference in these total values between different points of the hurricane is $\sim 100 \mathrm{~K}$ (Figure 17(a), Figure 17(b)). Of course, talking about a difference in radiation temperatures of $100 \mathrm{~K}$ between different points of the hurricane is completely meaningless. Therefore, it is difficult to agree that this technique is objective.

How can we separate the radiation temperature and PeTa radiation? It would seem that you can use the precipitation map (Figure 18). But it rains when the condensation is over. Therefore, we have to admit that at present, we do not have enough theoretical and experimental data to obtain real pictures of the distribution of temperature and PeTa radiation inside a hurricane. More research is needed. Their program is obvious: it is necessary to register the spectra of PeTa radiation in real conditions, compare them with pure Planck spectra under the same conditions, and develop a method for how to divide these spectra taking into account the instruments available on the satellites. If we do this, we get a real picture of the physical processes inside the hurricane. Taking into account the colossal destruction that hurricanes bring, the importance of real processes in them can hardly be overestimated.

\section{Luminescence of Bubbles}

In previous papers, we described PeTa models for a number of physical phenomena: cavitation luminescence/sonoluminescence (CL/SL) [8], laser-induced bubble luminescence (LIBL) [9] [10], and bubble luminescence in underwater geysers (VBL) [11]. The same category of natural phenomena includes a lightning strike into water (Figure 19). This is practically the same physical phenomenon that we observe when focusing a laser beam in water (LIBL). The primary areola when struck by lightning in water (Figure 19(a)) has a purple hue and is most likely associated with the formation of plasma within the vesicles. Then the glow disappears (Figure 19(b)), and after a moment, it appears again (Figure 19(c), Figure 19(d)), but already in the yellow-green light range. In all likelihood, this is VBL. In this case, apparently, both vapor bubbles in the water and bubbles that have risen into the airglow. Lightning striking a small river looks especially impressive. It spreads parallel to the surface at a certain depth, forming a vapor cloud. Unfortunately, its color is masked by silt and sand raised from the bottom. 


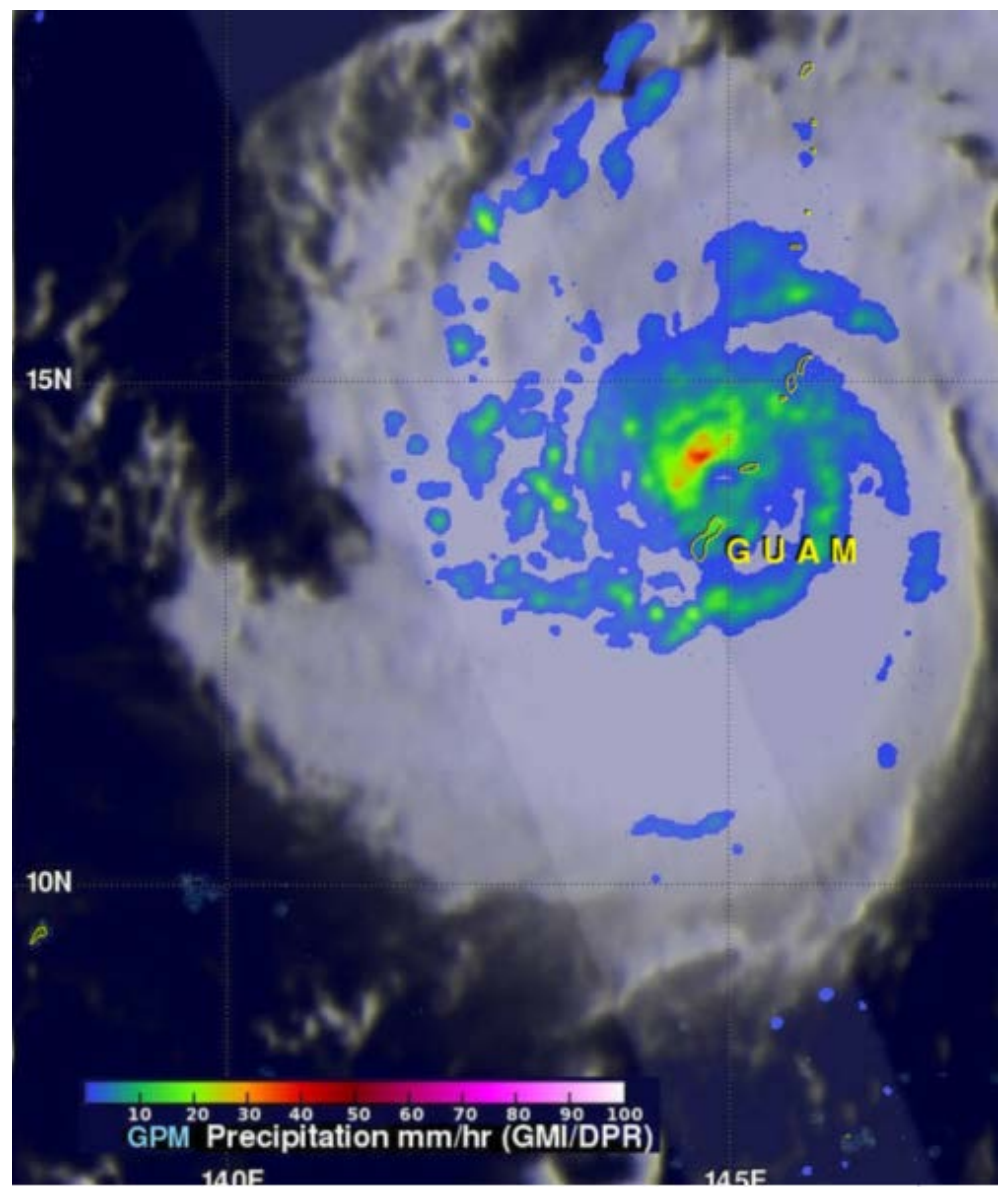

Figure 18. NASA's GPM Core observatory satellite captured this image of Dolphin just as the center was exiting the Rota Channel north of Guam. The image was taken at 10:16 UTC (8:27 pm, Guam time) on 15 May 2015 and shows the estimated rain rates within Typhoon Dolphin from the GPM Microwave Imager or GMI. GPM shows several well-defined rain bands (blue/green arcs) wrapping around the storm.

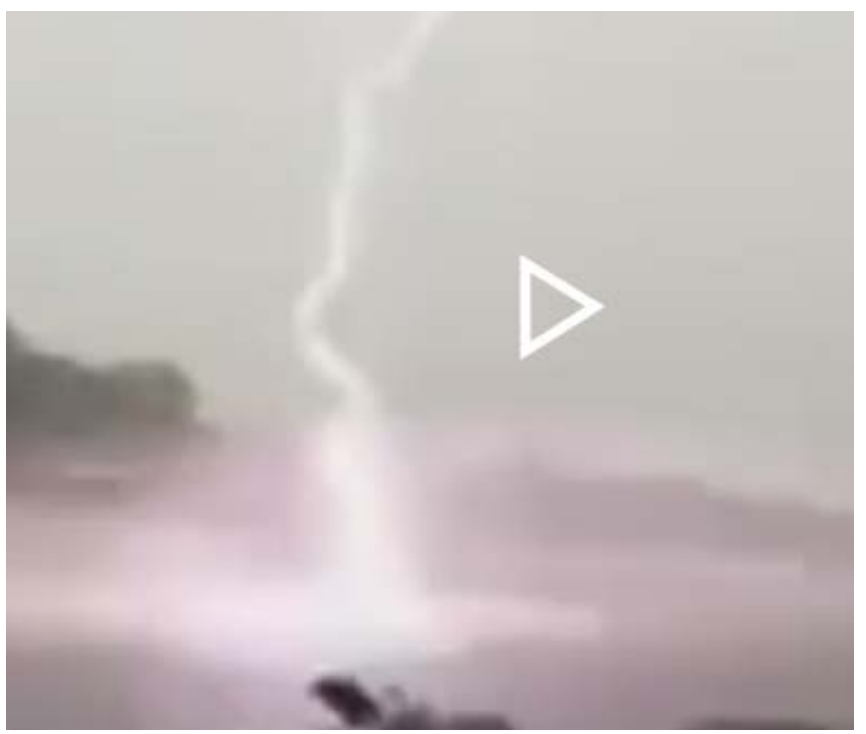

(a) 


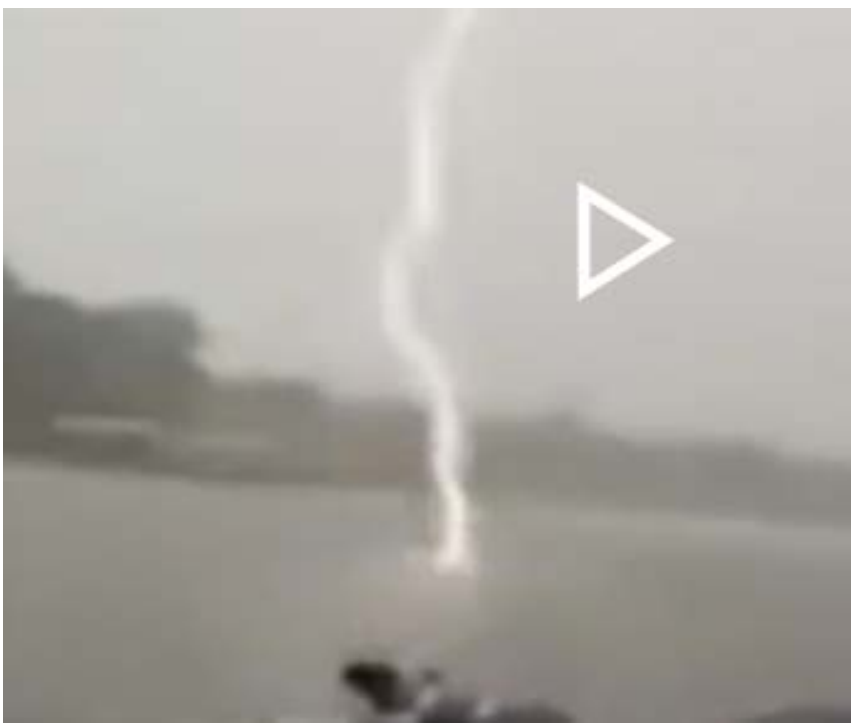

(b)

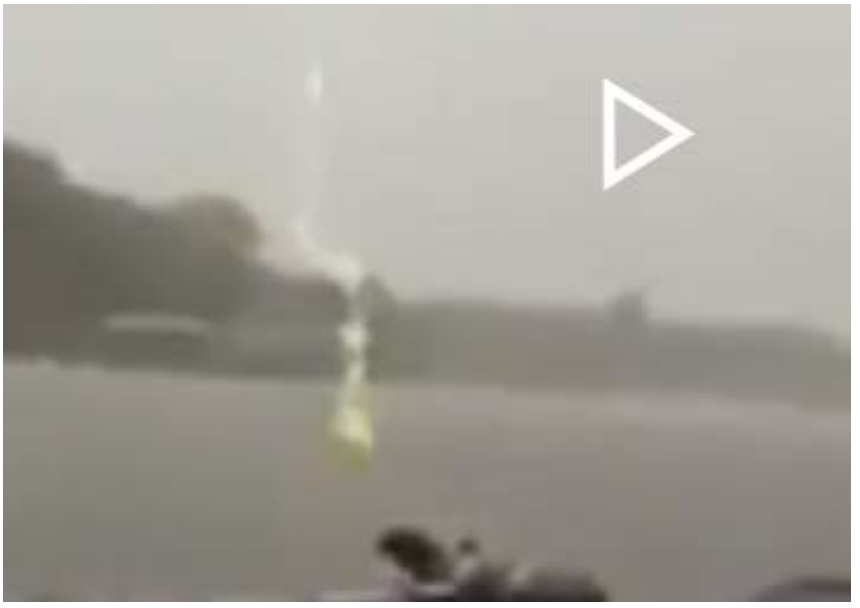

(c)

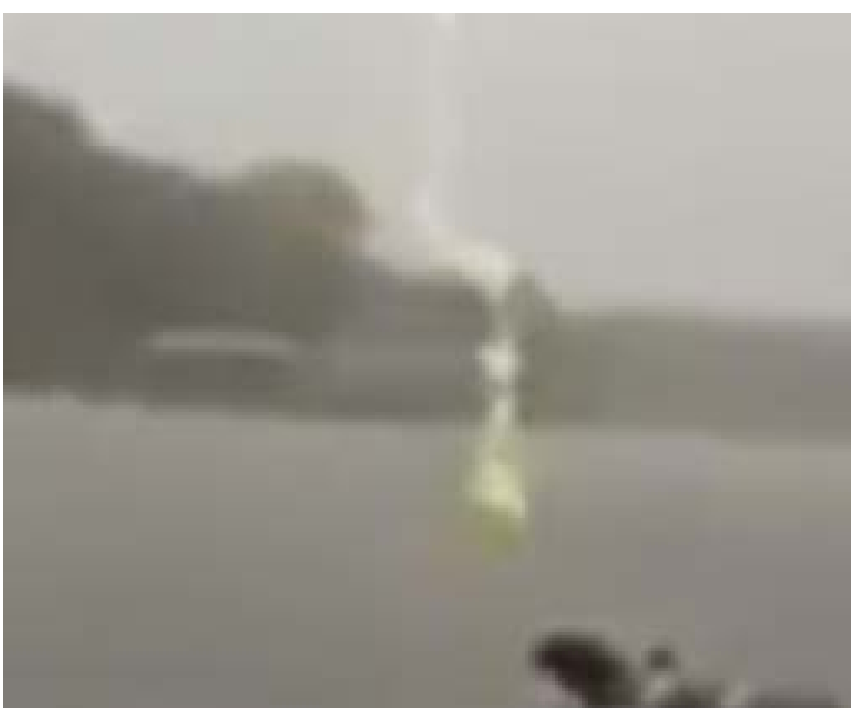

(d)

Figure 19. Lightning strike into water. 


\section{IR Radiation Preceding Earthquakes}

Although the huge energy that earthquakes release builds up for months and years beforehand in the form of stresses within the Earth's crust, up till now, forecasters have no direct reliable way of seeing these stresses or detecting when they reach critically high levels.

\subsection{Natural Observations of Infrared Radiation Preceding Earthquakes}

For the first time in the 1980s, the short-lived thermal anomalies before an earthquake in central Asia were recorded from satellite images [56]. Since then, many scientists from Russia, China, Japan, India, Iran, and Algeria have been studying satellite data concerning the thermal anomalies preceding earthquakes. Data of satellites such as NOAA/AVHRR and MODIS, which we already wrote about in $\$ 5$, were widely used for these studies. Several hundreds of observations of this type are described. Brief characteristics of the anomalies are: the short-lived thermal anomalies typically appear 2 - 14 days before an earthquake, affect from thousand to tens of thousands square kilometers, displayed a positive deviation of radiation temperature 2 - $4 \mathrm{~K}$ or more, and disappeared a few days after the event. Here are just a few examples.

Since 1990, the research group led by Z. Qiang, using the Meteorological satellite high-time resolution infrared images, has investigated numerous cases of infrared anomalies associated with earthquakes [57].

The thesis by Chunying Wang of Taiwan National Institute of Geography, Environment and Resources Research [58] reported that abnormal radiation temperature increase had been observed for 13 shallow-focus earthquakes of magnitude 5.9 during the period from 1999 to 2002.

Using MODIS data onboard the NASA Terra satellite, Allah-Zadeh and colleagues [59] repeatedly recorded infrared radiation in the wavelength range 3.66 - $3.84 \mu \mathrm{m}$ in 2003-2004 on the eve of earthquakes.

A M6.7 earthquake occurred on March 25, 2007 [60]. The NCEP data showed that surface radiation temperature increased about $6.2 \mathrm{~K}$ on March 23 compared to the temperature of March 22 (Figure 20(a), Figure 20(b)). The areas without obvious temperature increase are shown with grey, blue and green, and the area with higher temperature is shown with yellow and red. The high-temperature center corresponds to the future epicenter well. The temperature from February 25 to March 25 did not show other similar thermal anomalies.

Three Sumatra earthquakes occurred on February 8, 11, and 12 in 2007 with magnitudes M5.0, M5.7, and M5.0, respectively [50]. Four high-temperature centers appeared on January 16, 2007, and the right three centers corresponded to the three epicenters well (Figure 21(a), Figure 21(b)).

Very good reviews of the use of satellites for earthquake research up to 2012 with very impressive photos (Figure 22(a), Figure 22(b)) were realized by Tronin with coworkers [61]. 

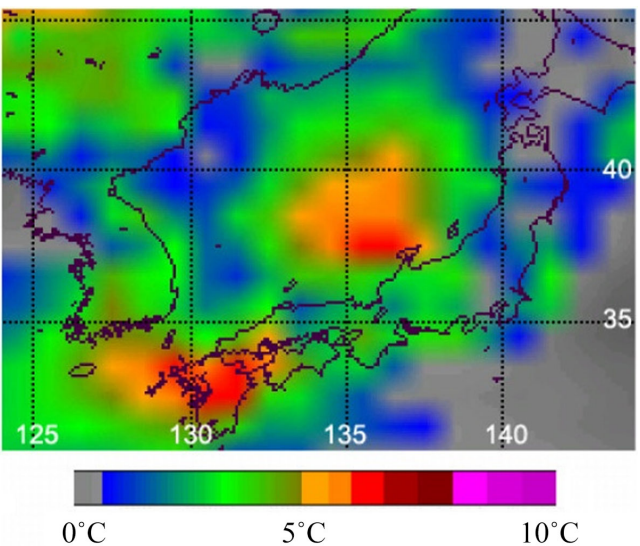

(a)

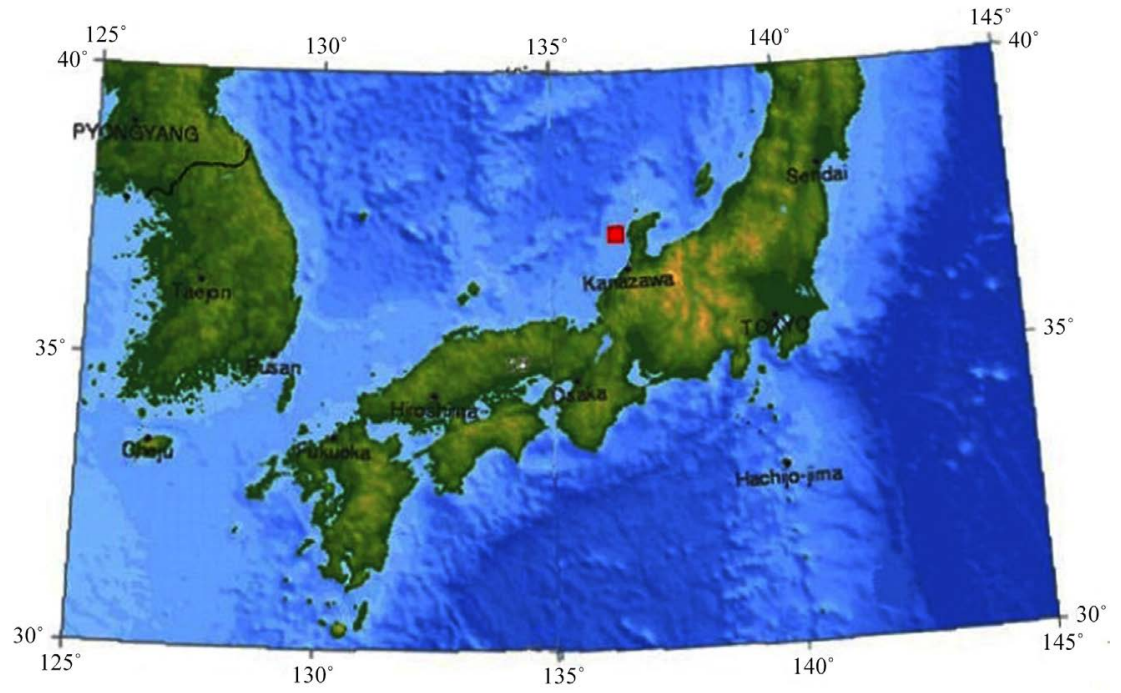

(b)

Figure 20. From [60] (a) The temperature anomaly before M6.7 earthquake of Japan; (b) The location of this quake.

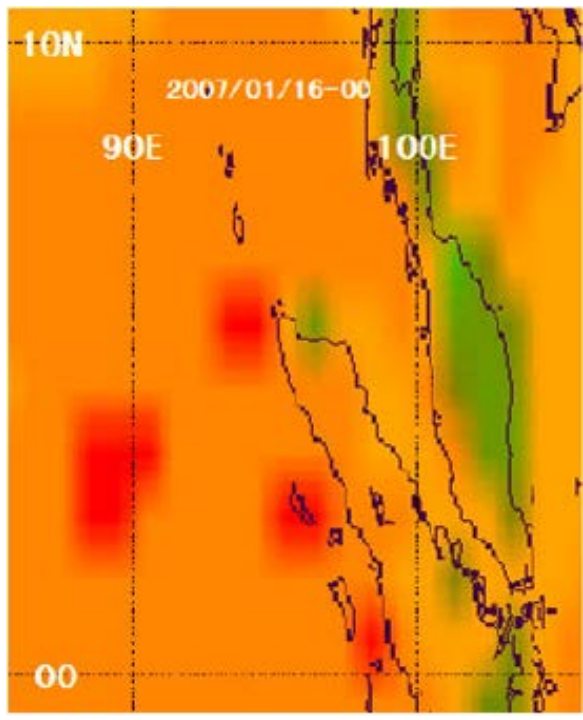

(a) 


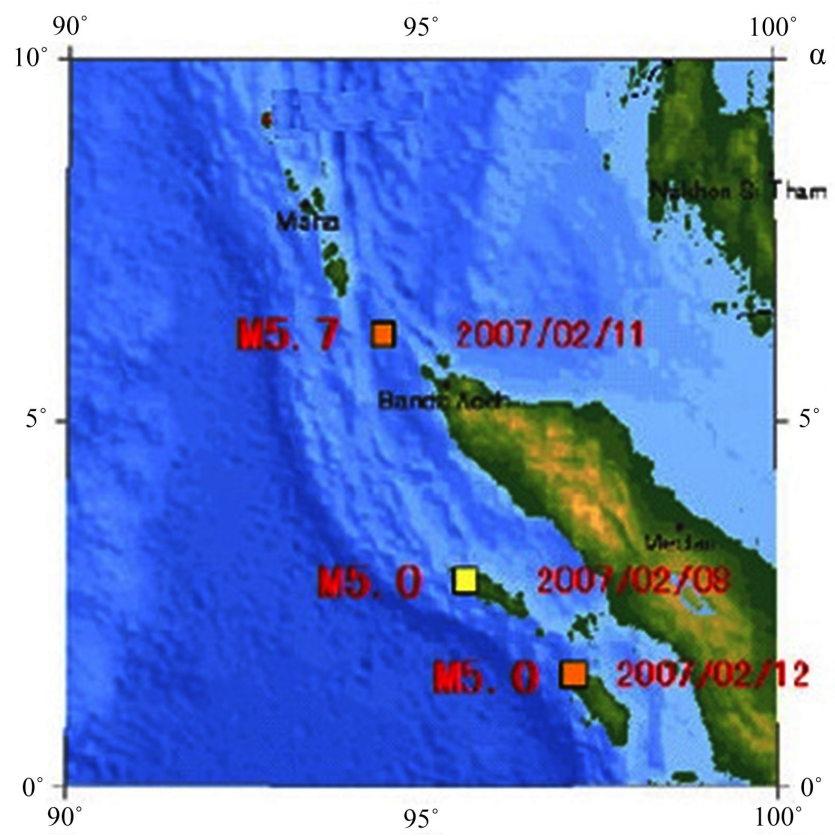

(b)

Figure 21. From [60] (a) Three temperature anomalies around Sumatra; (b) Three earthquakes.

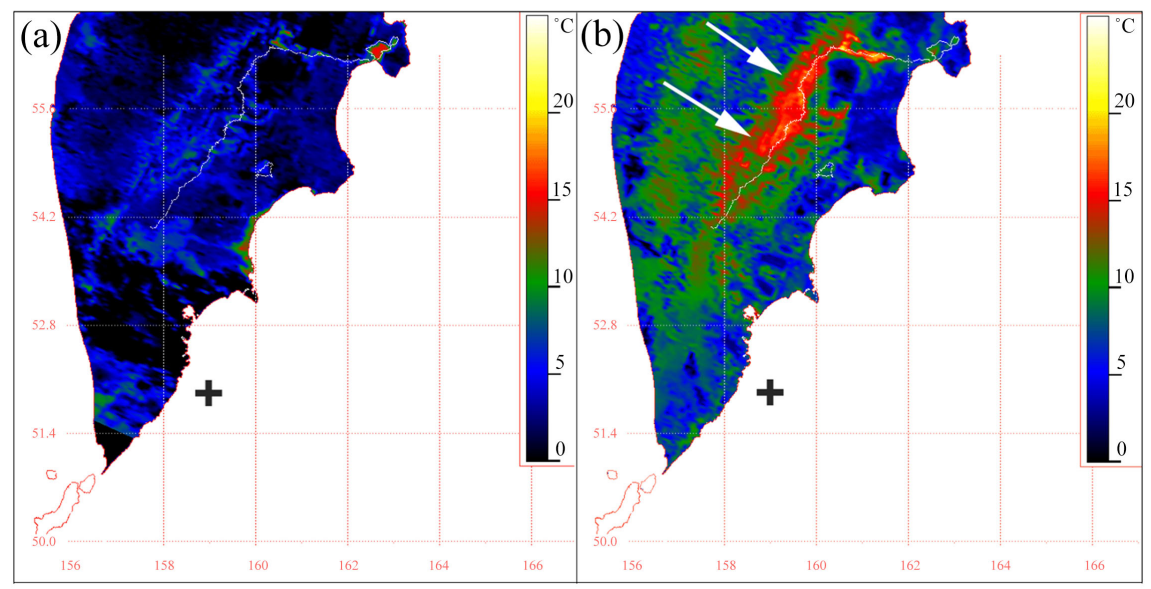

Figure 22. From [61] Thermal anomaly related with Kamchatka earthquake ( $M=7.0,21$ Jun 1996, Far East, Russia). (a) Background situation, satellite NOAA-14, 14 Jun 1996, cross-earthquake epicenter 21 Jun 1996. (b) Thermal anomaly, satellite NOAA-14, 22 Jun 1996, arrows show thermal anomaly, cross-earthquake epicenter

Wei with colleagues [62] studied the characteristics of thermal radiation observed before and after the 8 great earthquakes with magnitude up to M 7.0. They conclude that thermal anomalies can be used for earthquake prediction. In the paper [63], the authors reported a Robust Satellite data analysis Technique (RST) for the detection of seismic anomalies using the bi-angular Advanced Along-Track Scanning Radiometer (AATSR) gridded brightness temperature (BT). They investigated the Wenchuan earthquake that occurred on May 12, 2008. 


\subsection{The Simplest Hypothesis}

If on the basis of existing statistical data, we accept that infrared is the precursor and companion of earthquakes, a natural question arises: what is the physical nature of this radiation? Let us analyze several possibilities.

The simplest reason seems to be an increase in the Earth's apparent ground temperature. But there are at least three reasons why heating from below can be ruled out: 1) From known heat capacity data, it is possible to calculate that the energy required to heat by just $1^{\circ} \mathrm{C}$ such large volumes of rocks would exceed the total energy released during a $\mathrm{M} 7$ earthquake; 2) From known heat conductivity data, it is possible to calculate that such large volumes of rock can never heat up by several degrees and cool down again within a few days; 3) Figure 20(a) and Figure 21(a) clearly show that significant parts of the radiating surfaces are located under water. Thus, it cannot be a true temperature increase of the ground due to heat coming from below. Hence, we have to look for other causes.

\subsection{Laboratory Experiments}

Freund and coworkers carried out very interesting experiments on the study of infrared radiation emitted by rocks subjected to mechanical loading until failure [64]. A 1500-ton press at the Geophysical Laboratory (Figure 23(a), Figure 23(b)) was used. Emission spectra were recorded off a circular area, $5 \mathrm{~cm}$ diameter, from the flat front face of the rock, smooth "as received", i.e. as cut with a diamond saw (Figure 23(c)) with a Bomen MB-100 FT-IR spectroradiometer. It was equipped with a Peltier cooled $\mathrm{HgCdTe}$ detector and two integrated blackbody emitters for internal calibration, collecting the IR radiation sequentially from the sample and the two blackbody emitters. This Bomen MB-100 has been used extensively for laboratory and field calibrations for NASA's MODIS spectrometers currently flying on the TERRA and AQUA satellites. The spectra were recorded over the wavenumber range $7.14-14.25 \mu \mathrm{m}$ at $2 \mathrm{~cm}^{-1}$ resolution. Each FT-IR file consists of 25 scans off the rock surface plus 5 scans off the ambient temperature blackbody and 5 scans off the $60^{\circ} \mathrm{C}$ blackbody emitters for temperature calibration.

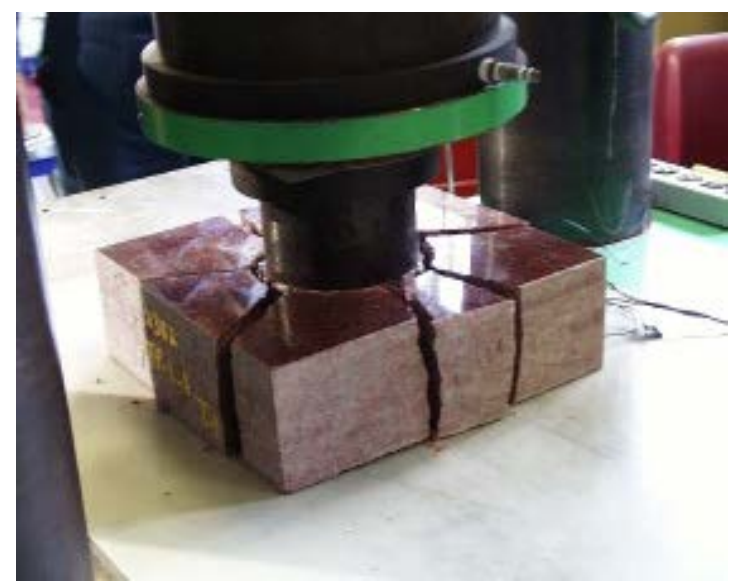

(a) 


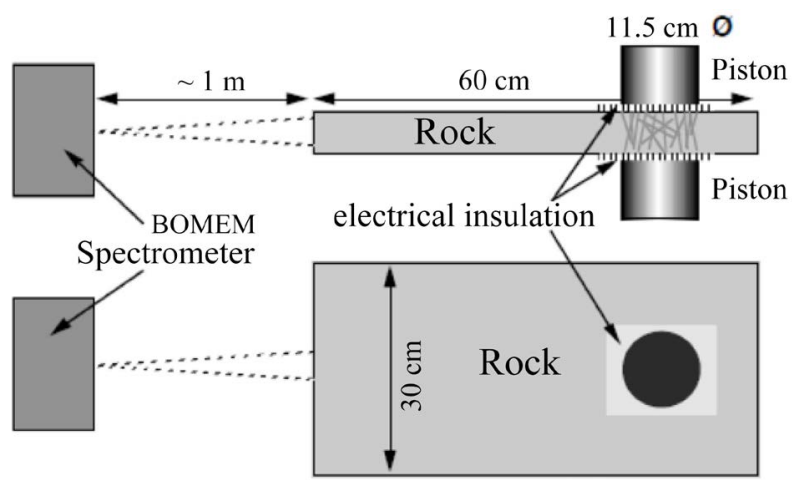

(b)

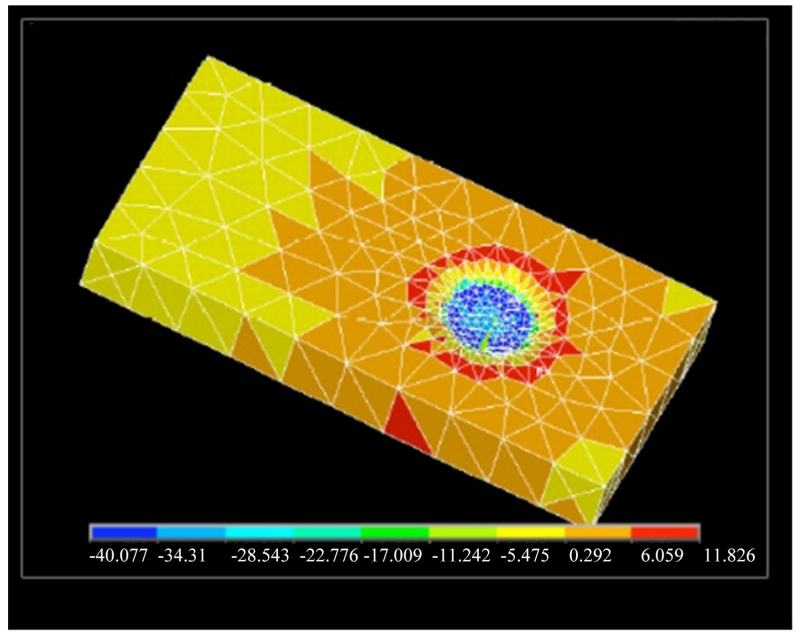

(c)

Figure 23. (a) From [64]. Schematic of the set-up used to measure the IR emission from the flat front face of a $60 \times 30 \times 7.5 \mathrm{~cm}^{3}$ block of anorthosite, loaded over $40 \mathrm{~cm}$ away from the emitting rock surface. (b) From [65]. When red granite is subjected to extreme crushing pressures in the laboratory, as in this experiment conducted by Freund and colleagues, its surface emits infrared radiation. (c) From [64]. Finite analysis representation, using a variable grid size, of the stress distribution in the anorthosite block during asymmetric loading. Yellow to blue signify compressive stresses, yellow to red tensile stresses. The surface from where the IR emission is measured (circular, square $\sim 20 \mathrm{~cm}^{2}$ ) is on the hidden surface on the upper left.

In Figure 24, the authors integrated the excess intensity emitted over the course of the experiment, from the beginning of loading to failure of the rock.

Several years before, the authors observed similar spectral features, in particular, narrow emission bands at the start of loading [65] [66] (Figure 25). Granite contained about 1/3 quartz, 1/3 plagioclase feldspar, and 1/3 potassium feldspar. Excess IR was emitted in narrow bands in the 10.5 - $12.5 \mu \mathrm{m}$ range plus some bands in the $8.7 \mu \mathrm{m}$ range. The present results confirmed these earlier observations, though the narrow emission bands from granite occurred at slightly different wavelengths, probably, due to its more complex mineralogy. 
Based on the analysis of surface electrification that appears during the deformation process, the authors propose the following explanation of the phenomenon under study: ordinary rocks are insulators. Rocks placed under great stress, however, act like semiconductors. Thus, the infrared emitted during phase transition is the phase transition energy. According to the authors of this study, this explanation has some support from experiments, but it's still a young hypothesis that hasn't gained widespread acceptance among scientists.

Figure 26 shows the granite appearing out of the ground close to Bahadoran fault southeast of Yazd. This is a confirmation of the colossal stresses in the earth's crust during earthquakes.

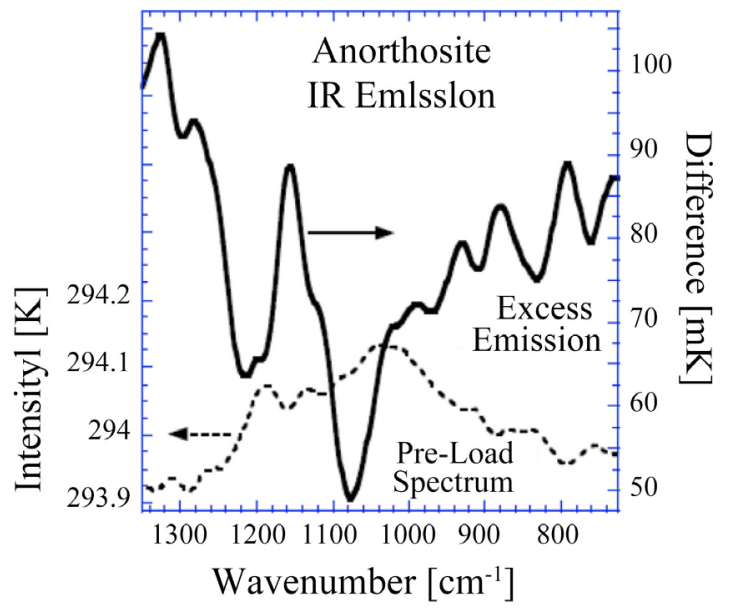

Figure 24. From [64]. Total excess intensity emitted over the $7.4-14.7 \mu \mathrm{m}$ range from the front face of the anorthosite block during loading (solid line) compared to the pre-load spectrum (dotted line).

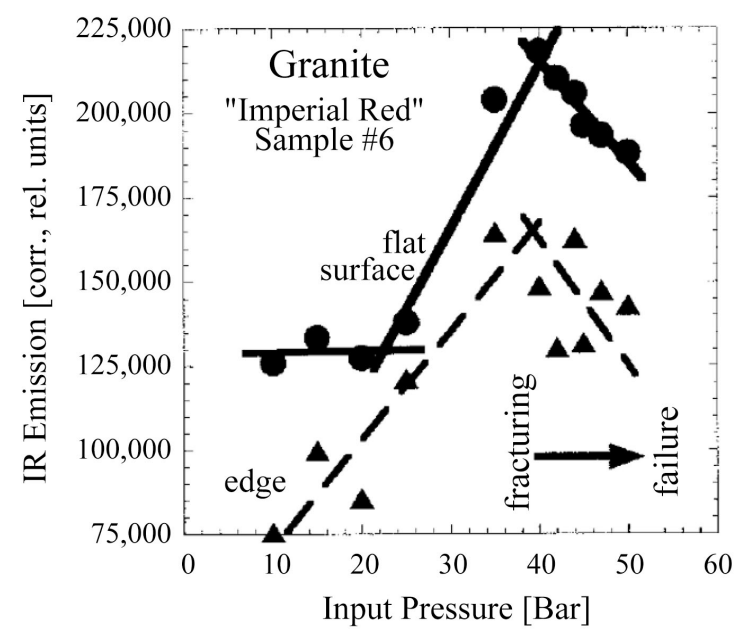

Figure 25. From [Freund, 2003]. Infrared emission from the flat surface and the edge of granite block undergoing deformation, measured with a QWIP camera at $8.5 \mu \mathrm{m}$. The observed infrared excess intensity is equivalent to a black body temperature increase of $0.5 \mathrm{~K}$. 


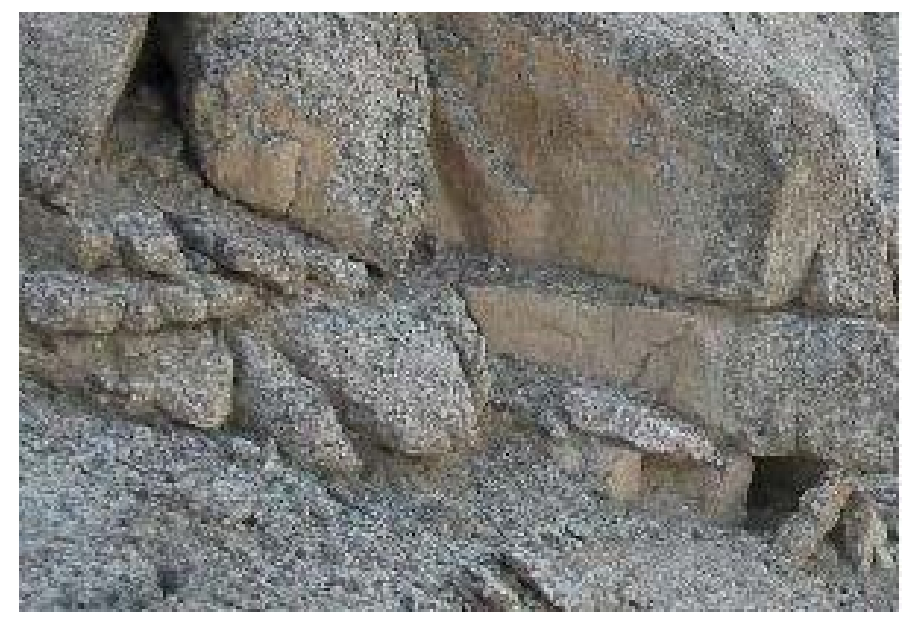

Figure 26. From [59] The granite appearing out of the ground close to the Bahadoran fault southeast of Yazd.

It should be noted that for physicists, the transformation of granite from an insulator into a semiconductor and the appearance of radiation in the process of deformation is not unexpected: As early as the 30s of the last century, in the process of deformation of some ionic crystals, the following were noted: 1) The appearance of electric charges on the opposite faces of the sample (Stepanov's effect); and 2) an increase in the electrical conductivity of the samples (GyulaiKhartly's effect) [67]. The author of this paper is well acquainted with the problem because I worked in Stepanov's Lab in Leningrad from 1959 to 1972, and in 1967, as a visiting scientist, I was invited to the Gyulai laboratory in Budapest for several weeks. Now, even students carry out laboratory work to study these effects in rocks (https://studopedia.ru/8_172378_effekt-stepanova.html). In those years, researchers associated these effects with the movement of electric charges in crystals and later with the movement of charged dislocations [67]. Regarding electromagnetic and infrared radiation, the mechanisms responsible for these effects appear to be different in various materials such as ionic crystals, ice, rocks, and metals [68] [69].

\subsection{A Complex Approach}

Analyzing all the possible causes of infrared and EM radiations on the eve of and after the earthquakes proposed in the literature, we cannot categorically reject any of them. Indeed, earthquakes occur in various geological areas with different weather conditions, and it is completely impossible to exclude the presence of conditions that implement one or another mechanism:

One of the offered causes is warm gases that may be released from faults. To account for the lateral extent of thermal anomalies and their apparent homogeneity, it has been suggested that warm gases propagate along the ground or create local greenhouse conditions [56].

Another mechanism is proposed by Liperovsky with colleagues [70]: the non-stationary Frenkel model of the generator of spikes of the local electric field 
with time scales of $1-100 \mathrm{~min}$ in the atmosphere near seismic fracture regions some days before strong earthquakes is analyzed. The model suggests an aerosol cloud, an increased ionization velocity (e.g. by radon emanation), and an upward flow of air. It was found that during times of earthquake activity (that means a few days before an earthquake), for realistic increases of the ionization intensity of the atmosphere, mosaic-like occurring and disappearing pulses of local electric fields with intensities of the order of $10^{3}-3 \times 10^{3} \mathrm{Vm}^{-1}$ should be observable. These electric fields would also cause spikes of non-equilibrium IR emissions $(0.7-20 \mu \mathrm{m})$ and local spikes of the magnetic field.

Khatiashvili and Perel'man [71] proposed a model of generation of low- and radio-frequency electromagnetic (EM) radiation by seismic waves of pressure applied to a neutral non-piezoelectric medium. The EM radiation is induced during the process of ionic crystal fracture and formation of a mosaic of fluctuation charges on the opposite sides of the cracks, the formation and oscillation of charged dislocations, and the vibrations of very small conducting or magnetized particles in dielectrics with fluctuating charges proportional to their radius and temperature. The most interesting source of EM emission is the process of formation and oscillation of double electric layers (DEL). The DEL can be presented as a system of capacitors or electric dipoles. The variation of their parameters by external pressure, by changes of water content, etc., leads directly to the EM emission. As DELs are widespread in rocks, they can make an essential contribution to EM radiation. DEL oscillation induced by tectonic processes is probably the main contribution.

Ouzounov with colleagues [72] [73] insists that the thermal heat fluxes over areas of earthquake preparation are a result of air ionization by radon (and other gases) and consequent water vapor condensation on newly formed ions. Latent heat $(\mathrm{LH})$ is released as a result of this process and leads to the formation of local thermal radiation anomalies (TRA) known as OLR (outgoing longwave radiation). They compared the LH energy, obtained by integrating surface latent heat flux (SLHF) over the area and time with released energies associated with these events. Extended studies of the TRA using the data from the most recent major earthquakes allowed establishing the main morphological features. It was also established that the TRA is part of a more complex chain of the short-term pre-earthquake generation, which is explained within the framework of lithosphere-atmosphere coupling processes. We are particularly impressed by the last hypothesis about the condensation of water vapor on charged radon ions, as a result of which the PeTa energy of water vapor condensation should be emitted. We analyzed similar processes in $\$ 3$.

\section{PeTa Effect and Global Warming}

The problem of global warming on our planet is one of the main scientific problems discussed in the general press. Global warming is an obvious fact. This is evidenced not only by the increase in average annual temperatures, but also by 
the rapid decrease in the area of large glaciers, and the recently appeared opportunity to travel the entire distance of the Northern Sea Route in one navigation. Further development of these processes can lead to catastrophic flooding of many low-lying regions of the globe. Of course, keeping in mind the times when mammoths died out from the cold or vice versa-Greenland was covered with lush vegetation, we cannot exclude the fact that this is just another cycle in the life of our planet. We know the nature of this cyclicality-a periodic change in the inclination of the earth's axis, which we cannot influence. But if there is any impact of human activity on global warming, we need to minimize this impact. A more radical approach is also possible to prevent global warming as a result of changes in human activity, i.e. it is necessary to stop doing something and/or start doing something. But you need to clearly understand what. What do we see in reality? Instead of a comprehensive scientific analysis of the situation, a single culprit was appointed, and a decisive struggle began against him.

This culprit is declared to be an increase in the content of carbon dioxide in the atmosphere and, as a result, an increase in the greenhouse effect. The greenhouse effect does exist. It was discovered by Joseph Fourier in 1827. Its essence lies in the fact that solar radiation, heating the Earth, is mainly in the optical range, and in the process of cooling, the Earth radiates energy into space in the infrared range. The reason for this phenomenon is very simple: the Earth is covered by an atmosphere that contains gases that are more transparent in the optical range. Therefore, the Earth emits less energy than it receives from the sun. Thus, the atmosphere plays the role of a blanket (greenhouse cover) for the Earth and contributes to an increase in its temperature. Without the greenhouse effect, life on Earth in its present form would be impossible due to the low temperature. But an increase in the greenhouse effect is also undesirable since it leads to an increase in temperature. The main greenhouse gases are water vapor, carbon dioxide, and, to a lesser extent, methane and ozone. Why is the focus on carbon dioxide? The content of carbon dioxide in the Earth's atmosphere has increased in recent years. This is natural, since working plants and factories, and especially automobiles, emit carbon dioxide into the atmosphere. Instead of a comprehensive analysis of the situation, this gas is hastily designated as the main culprit in the warming. In 1997, the Kyoto Treaty was drawn up. The 156 signatory countries are pledging to spend billions of dollars to reduce carbon dioxide emissions. True, President D. Trump found reasonable consultants, and the United States withdrew from this agreement, but President Joe Biden considered it necessary to return the United States to the Kyoto community.

The first thing that catches your eye is that water vapor is generally forgotten (recall the statement given at the beginning of the paper [12]). The amount of water vapor in the atmosphere, all other things being equal, depends on the area of the evaporating surface. It is known that the earth's surface, covered with intense vegetation, evaporates in the same way as the water surface. But the development of civilization reduces green surfaces because forests are being cut down, swamps are drained, the ground is covered with asphalt and concrete during the 
construction of new cities, roads, and extensive parking lots. This reduces the amount of water vapor in the atmosphere. Why are these processes analyzed only by a small group of enthusiasts?

We are not going to globally analyze the warming situation. Our task is to point out an obvious miscalculation in assessing the role of water vapor and to show that the PeTa effect also plays an important role in the heat balance of the Earth, contributing to the removal of thermal energy into space.

At present, we do not have sufficient experimental material to analyze this issue quantitatively. For qualitative analysis, we can use the following facts:

1) In $₫ 1$ we showed that the PeTa radiation during the formation of clouds is directed toward the earth.

2) But in the same place, we showed that the PeTa radiation formed during the condensation of vapor over the desert, in the absence of clouds, is carried away into space.

3 ) In $₫ 3$, we showed that it is released during the formation of clouds in the mountains, on the sea coasts, etc. PeTa energy is observed from satellites. Thus, this energy is carried away into space and thus counteracts the greenhouse effect. The power of this radiation is $50-90 \mathrm{~mW} / \mathrm{m}^{2} \cdot \mathrm{str} \cdot \mu \mathrm{m}$.

4) In $\$ 5$, we showed that the entire earth's atmosphere mainly radiates energy in the $6.7 \mu \mathrm{m}$ range. The power of this energy is directly proportional to the relative humidity of the atmosphere. This is quite natural for PeTa radiation since its capacity is proportional to the rate of condensation, which in turn is proportional to the relative humidity.

5) In $₫ 8$ we showed that the PeTa radiation arising from the formation of tropical storms is carried away into space.

6) Thus, given that four facts are stated above in favor of the cooling effect of PeTa radiation and one fact in favor of the greenhouse effect, the contribution of both these effects to the Earth's heat balance needs careful analysis. Currently, there are many measurements that show that when large areas are freed from vegetation, the local average annual temperature rises. Thus, a decrease in the content of water vapor in the atmosphere reduces the cooling of the Earth through the PeTa effect to a greater extent than reduces the heating of the Earth due to the greenhouse effect. It seems to us that the money thoughtlessly spent on reducing carbon dioxide emissions into the atmosphere should be spent on watering deserts and restoring deforested forests. In this case, there would be an obvious double benefit-both an increase in the content of water vapor in the atmosphere and an increase in the area of land used.

\section{Conclusions}

1) The PeTa effect is a complete or partial emission of the energy of phase transitions of the first order when the transition occurs from a less condensed phase to a more condensed one. In the earth's atmosphere, such transitions are the formation of fog, clouds during vapor condensation and hail, snow during 
vapor deposition. In this case, the PeTa radiation should be found mainly in the atmospheric transparency window of $6.5-14 \mu \mathrm{m}$.

2) It was in this range that more than 50 years ago radiation was recorded during the formation and destruction of clouds, during the formation of haze over the desert and on the slopes of mountains (most likely during the formation of clouds).

3) Several groups of researchers, based on the analysis of satellite data, report numerous zones of anomalous IR radiation. They associate this radiation with the release of endogenous heat through faults in the earth's crust. We prove that in all cases, this is PeTa radiation during the formation of clouds and fog. We propose to accumulate PeTa energy by creating a pulse laser.

4) A group of researchers recorded individual pulses of infrared radiation in a clear sky. We show that these are flashes of PeTa radiation during condensation explosions in the atmosphere. This is an instant condensation of a significant volume of supercooled steam. Condensation explosions leave condensation craters which exist for a long time and are detected by meteorological probes. The formation of condensation explosions was simulated under laboratory conditions.

5) To measure the concentration of water vapor in the atmosphere from satellites, atmospheric radiation in the $6-8 \mu \mathrm{m}$ range is used. Researchers do not understand that this is PeTa radiation. This does not allow one to interpret the experimental data correctly and sometimes even leads to their directly opposite interpretation.

6) The nature of atmospheric scintillations in the IR range is explained by the PeTa effect.

7) PeTa radiation is the reason for the comfortable conditions in ice housesigloos. Before a thunderstorm, PeTa radiation can cause strong stuffiness, which disappears with the first raindrops. PeTa radiation should be taken into account when determining the actual temperature experienced by humans.

8) When tropical storms form, a lot of water vapor condenses. This leads to intense PeTa radiation. However, the standard data processing technique perceives this radiation as Planck radiation, which corresponds to an unrealistically high radiation temperature. This does not allow us to understand the nature of these physical processes.

9) The luminescence of vapor bubbles formed when lightning strikes water is of the same nature as cavitation luminescence.

10) Emissions preceding the earthquake were observed many times. Their nature has not yet been clarified. The most probable reasons can be both phase transitions in rocks under the action of intense loads and PeTa radiation during vapor condensation on charged ions.

11) The influence of the PeTa effect on global warming cannot be considered in isolation from the general influence of water vapor. To our surprise, this issue is largely ignored by researchers, although the data already available is sufficient 
to understand that this effect is stronger than the effect of carbon dioxide. It is necessary to increase the content of water vapor in the atmosphere.

\section{Conflicts of Interest}

The author declares no conflicts of interest regarding the publication of this paper.

\section{References}

[1] Perel'man, M.E. (1971) Phase Transitions Caused by the Opening of New Channels in Electron-Photon Interactions. Physics Letters A, 37, 411-412. https://doi.org/10.1016/0375-9601(71)90609-8

[2] Tatarchenko, V.A. (1979) Appearance of Distinguishing Features in Emission Spectra during Crystallization of Substances Transparent in the IR Region. Soviet Physics-Crystallography, 24, 238-239.

[3] Umarov, L.M. and Tatarchenko, V.A. (1984) Differential Spectra of Crystallization Radiation of Alkali-Metal Halides. Soviet Physics-Crystallography, 29, 670-673.

[4] Tatarchenko, V.A. and Umarov, L.M. (1980) Infrared Radiation Accompanying the Crystallization of Sapphire. Soviet Physics-Crystallography, 25, 748-749.

[5] Ravilous, K. (2010) Cloud Power. New Scientist, 208, 38-41. https://doi.org/10.1016/S0262-4079(10)62951-X

[6] Tatartchenko, V.A., Smirnov, P.V. and Wu, Y. (2013) First Order Phase Transitions as Radiation Processes. Optics and Photonics Journal, 3, 1-12. https://doi.org/10.4236/opj.2013.38A001

[7] Tatartchenko, V.A., Smirnov, P.V. and Jin, H. (2014) First Order Phase Transitions as Radiation Processes, Part Two. Optics and Photonics Journal, 4, 26-37. https://doi.org/10.4236/opj.2014.42005

[8] Tatartchenko, V.A. (2017) Sonoluminescence as the PeTa Radiation. Optics and Photonics Journal, 7, 27-55. https://doi.org/10.4236/opj.2017.72004

[9] Tatartchenko, V.A. (2017) Sonoluminescence as the PeTa Radiation, Part Two. Optics and Photonics Journal, 7, 197-220. https://doi.org/10.4236/opj.2017.711019

[10] Tatartchenko, V.A. (2018) Sonoluminescence as the PeTa Radiation, Part Three. Optics and Photonics Journal, 8, 187-200. https://doi.org/10.4236/opj.2018.86017

[11] Tatartchenko, V.A. (2019) Bubble Glow at Hydrothermal Vents as the PeTa Radiation. Optics and Photonics Journal, 9, 189-217. https://doi.org/10.4236/opj.2019.911017

[12] Lindzen, R.S. (1990) Some Uncertainties with Respect to Water Vapor's Role in Climate Sensitivity. Proceedings of NASA Workshop on the Role of Water Vapor in Climate Processes, 29 October-1 November 1990, Easton, 151 p.

[13] Nichols, L.W. and Lamar, J. (1968) Conversion of Infrared Images to Visible in Color. Applied Optics, 7, 1757-1762. https://doi.org/10.1364/AO.7.001757

[14] Ramanathan, V., Cess, R.D., Harrison, E.F., Minnis, P., Barkstrom, B.R., Ahmad, E. and Hartmann, D. (1989) Cloud-Radiative Forcing and Climate: Results from the Earth Radiation Budget. Science, 243, 57-63. https://doi.org/10.1126/science.243.4887.57

[15] Yasenovsky, A.A. (2004) Radon and Thermal Active Faults BRZ (Tuna and Barguzin Valleys), Their Environmental Impact. Materials of the Scientific Conference “Modern Problems of Geochemistry", Irkutsk, 20-23 April 2004, 75-79. (In Russian) 
[16] Lisak, S.V. (1996) Geothermal Southern Regions of Eastern Siberia. In: Logachev, N.A. and Levy K.G., Eds., Proceedings of Geophysical Exploration in Eastern Siberia at the Turn of the XXI Century, Science, Siberian Publishing House of RAS, Novosibirsk, 17-23 (In Russian)

[17] Vilor, N.V., Rusanov, V.A. and Sharpinsky, Yu.D. (2009) The Distance Probing of the Earth Method for Research of the Outgoing Infrared Radiation of the Surface Geo-Structure of Northwestern China (Xinjiang). In: Lupyan, E.A., Ed., Modern Problems of Distance Probes of Earth from Space, Vol. 6, Institute of Space Research, Moscow, 24-35..

[18] Gorny, V.I., Latypov, I.S., Tepliakova, T.E. and Voyakina E.Y. (2009) Verification of Remote Geothermal Method Results at the Big Solovetskii Island While Investigation of Reasons of Extra Zonal Ecosystem Formation. In: Lupyan, E.A., Ed., Modern Problems in Remote Sending of the Earth from Space, Vol. 6, Institute of Space Research, Moscow, 36-45. (In Russian)

[19] Vilor, N.V. and Min'ko, N.P. (2001) Infra-Red Radiation of the Baikal-Sayan Mountain Area and Baikal Rift Zone on the Basis of Data of Satellite's Monitoring. Reports of Russian Academy of Sciences, 379, 666-669. (In Russian)

[20] Vilor, N.V. and Abushenko, N.A. (2002) The Contemporary IR-Radiation of Regional Faults, Its Nature and Application for Satellite Monitoring of Seismic Active Tension State of Central Asia. Proceedings of the International Seminar Asia-Pacific Space Geodynamics Program, Irkutsk, 5-10 August 2002, 199-205.

[21] Vilor, N.V. and Min'ko, N.P. (2002) Satellite's Monitoring of Infrared Radiation of Structural Elements in the Baikal-Sayan Mountain Area. Investigation of the Earth from Space, No. 4, 55-61. (In Russian)

[22] Vilor, N.V. and Min'ko, N.P. (2003) Infrared Radiation of Structural Elements in the Baikal-Sayan Mountain Area. Geography and Natural Resources, No. 2, 50-55. (In Russian) http://www.sibran.ru/English/geogre.htm

[23] Vilor, N.V., Abushenko, N.A. and Tastchilin, S.A. (2006) Satellite's Method of investigation of Correlation between Infrared Emission Flux and Elements of Geological Earth's Structure in the North's Hemisphere. In: Lupyan, E.A., Ed., Modern Problems of Distance Probes of Earth from Space, Vol. 3, Institute of Space research, Moscow, 215-224. (In Russian)

[24] Vilor, N.V., Tashchilin, S.A., Kluchevsky, A., Demyanovich, V., Kuznetsova, A., Zarubina, O., Rusanov, V.A. and Sharpinsky, Yu. D. (2008) Remote Sensing in Investigating the Infrared Radiation Escaping from Regional Faults, and Its Geophysical and Geochemical Components. Abstract of 33rd IGC International Geological Congress, Oslo, 6-14 August 2008.

[25] Vilor, N.V., Klyuchevskii, A.V., Dem'yanovich V.M., Rusanov, V.A., Tashchilin S.A. and Sharpinsky, Yu. D., (2008) Distribution and Vibrational Properties of the Outgoing IR Surface Faults Flow in Correlation Ratios with Seismological Parameters. In: Lupyan, E.A., Ed., Modern Problems of Distance Probes of Earth from Space, Vol. 5, Institute of Space Research, Moscow, 337-348.

[26] Vilor, N.V., Abushenko, N.A. and Tastchilin S.A. (2004) Infrared Radiation of Earth in Region of Joining Ocean-Continent. Investigation of the Earth from Space, No. 2, 17-24. (In Russian)

[27] Niksich, I.I. (1925) Kopet-Dag Line Thermal Waters. Bulletin of Irrigation, No. 7, 65-82.

[28] Vilor, N.V., Abushenko, N.A. and Lepin, V.S. (2003) Infrared Radiation of Earth's Surface in the Zone of Arid Climate. Reports of Russian Academy of Sciences, 388, 
647-650. (In Russian)

[29] Morozova, L.I. (2005) Detection of Linear Cloudy Anomalies above the Caspian Sea Faults Using Satellite Imagery. Investigation of the Earth from Space, No. 2, 27-30. (In Russian)

[30] Letnikov, F.A. (1992) Synergetic of Geological Systems. Science, Novosibirsk, 228 p. (In Russian)

[31] Vilor, N.V. (2003) Invisible Earth's aureole. Chemistry and Life, No. 5, 40-42. (In Russian)

[32] Bordonskiy, G.S. (1990) Probable Traces of the Laser Emission of Natural Atmospheric Origin. Atmospheric and Oceanic Optics, 3, 352-355.

[33] Bordonskiy, G.S. and Gurulev, A.A. (2008) Measurements of the Thermal Emission of Chita Atmosphere in the Magnetic Storm of 14 December 2006. In: Matvienko, G.G. and Banakh, V.A., Eds., Abstracts of 14 th International Symposium on Atmospheric and Ocean Optics/Atmospheric Physics, Tomsk, 24-30 June 2007, Article No. 69361U. https://doi.org/10.1117/12.783669

[34] Bordonskiy, G.S. (2010) Retrieval of Active Environments (Remarks on Article of V.A.Tatartchenko "Nature of Some Sources of Atmospheric Infrared Radiation"). Investigation of Earth from Space, No. 2, 90-92.

[35] Jenkins, J. (2012) Water Vapor Rising. https://vaporrising.wordpress.com

[36] Seporaitis, M., Pabarcius, R. and Almenas K. (2002) Study of Controlled Condensation Implosion Events. Proceedings of 10 th International Conference on Nuclear Engineering Arlington-ICONE10, Arlington, 14-18 April 2002, Paper No. ICONE22448. https://doi.org/10.1115/ICONE10-22448

[37] Pabarcius, R., Šeporaitis, M. and Almenas, K. (2004) Investigation of Condensation Implosion Event. Heat Transfer Research, 35, 531-548. https://doi.org/10.1615/HeatTransRes.v35.i78.70

[38] Almenas, K., Seporaitis, M. and Pabarcius, R. (2006) Design and Tests of a Device for the Generation of Controlled Condensation Implosion Events. Heat Transfer Engineering, 27, 32-41. https://doi.org/10.1080/01457630500458047

[39] Seporaitis, M., Valincius, M., Pabarcius, R. and Babilas, E. (2010) RELAP5 Analysis of Circulation Driven by Condensation Implosions. Energetika, 7, 232-237. (In Lithuanian)

[40] Valincius, M., Seporaitis, M., Gasiunas, S., Laurinavičius, D., Pabarcius, R., Kaliatka, A. and Almenas, K. (2016) Investigation of Interfacial Interaction and Condensation. Energetika, 62, 206-218. (In Lithuanian) https://doi.org/10.6001/energetika.v62i3.3355

[41] Hasler. F., Chesters, D., et al. (2003) GOES Project, NASA/GSFC. Astronomy Picture of the Day. National Aeronautics and Space Administration, Washington D.C. http://antwrp.gsfc.nasa.gov/apod/ap020323.html

[42] Curtis, A.R. (1994) Space Satellite Handbook. Gulf Publishing, Houston, 346 p.

[43] Bader, M.J., Forbes, J.R., Grant, J.R., Lilley, R.B. and Waters, A.J. (1995) Images in Weather Forecasting: Practical Guide for Interpreting Satellite and Radar Data. University Press, Cambridge.

[44] Soden, B.G. and Lanzante, J.R. (1996) Interpretation of TOVS Water Vapor Radiances in Terms of Layer-Average Relative Humidities: Method and Climatology for the Upper, Middle, and Lower Troposphere. Journal of Geophysical Research, 101, 9333-9343. https://doi.org/10.1029/96JD00280

[45] Al-Hourani A., Evans, R.J., Farrell, P.M., Moran, B., Martorella, M., Kandeepan, S., 
Skafidas, S. and Parampalli, U. (2017) Chapter 7: Millimeter-Wave Integrated Radar Systems and Techniques. In: Theodoridis, S., Chellappa, R. and Gini, F., Eds., Academic Press Library in Signal Processing (SIGP): Array, Radar and Communications Engineering, Vol. 7, Elsevier, Amsterdam, 317-363. https://doi.org/10.1016/B978-0-12-811887-0.00007-9

[46] Ostrovsky, E.V. (2009) Assessment Parameters in Hardware Complex Sharing IR and Microwave Radiometers for Humidity Sounding Troposphere. Proceedings of III All-Russian Conference "Radiolocation and Radio Communications"-IRE, Moscow, 26-30 October 2009, 640-644.

[47] Carlon, H.R. (1965) The Apparent Dependence of Terrestrial Scintillation Intensity upon Atmospheric Humidity. Applied Optics, 4, 1089-1097. https://doi.org/10.1364/AO.4.001089

[48] Holihan, R., Keeley, D., Lee, D., Tu P. and Yang E. (2003) How Warm Is an Igloo? BEE 453, Cornell University, Ithaca. http://www.ecommons.cornell.edu/bitstream/1813/125/2/Igloo.pdf

[49] Tatartchenko, V.A. (2005) Sapphire Crystal Growth and Application. In: Capper, P., Ed., Bulk Crystal Growth of Electronic, Optical and Optoelectronic Materials, Wiley \& Sons, Hoboken, 300-338. https://doi.org/10.1002/9780470012086.ch10

[50] Fauzi, R.R. and Lin, Y. (2015) Assignment 2, Part 2 (Group Project) Materials in Vernacular Architectures: Validation of Sustainability. SUSD0002-Resources, Materials and Sustainability, UNSW Sydney, Kensington.

[51] Charney, J.G. and Eliassen, A. (1964) On the Growth of the Hurricane Depression. Journal of Atmospheric Sciences, 21, 68-75.

https://doi.org/10.1175/1520-0469(1964)021\%3C0068:OTGOTH\%3E2.0.CO;2

[52] Mareček, S.V., Ermakov, M.D. and Smirnov, M.T. (2012) The Accumulation of Vapor in the Atmosphere during the Period of the Threat or the Origin of Passing Storms. Modern Problems of Remote Sensing of the Earth from Space, 9, 142-148.

[53] Dvorak, F.V. (1975) Tropical Cyclone Intensity Analysis and Forecasting from Satellite Imagery. Monthly Weather Review, 103, 420-430. https://doi.org/10.1175/1520-0493(1975)103\%3C0420:TCIAAF\%3E2.0.CO;2

[54] Velden, C.S., Olander, T.L. and Zehr, R.M. (2007) Development of an Objective Scheme to Estimate Tropical Cyclone Intensity from Digital Geostationary Satellite Infrared Imagery. Weather and Forecasting, 13, 172-186. https://doi.org/10.1175/1520-0434(1998)013\%3C0172:DOAOST\%3E2.0.CO;2

[55] Pineros, M.F., Ritchie, E.A. and Tyo, J.S. (2011) Estimating Tropical Cyclone Intensity from Infrared Image Data. Weather and Forecasting, 26, 690-698. https://doi.org/10.1175/WAF-D-10-05062.1

[56] Gorny, V.I., Salman, A.G., Tronin, A.A. and Shilin, B.B. (1988) The Earth Outgoing IR Radiation as an Indicator of Seismic Activity. Proceeding of the Academy of Sciences of the USSR, 301, 67-69.

[57] Qiang, Z. (2001) Satellite-Based Prediction of Earthquakes. News Letter, EARSEL, No. 47, 21-26.

[58] Wang, C.-Y. (2005) Applying Spatio-Temporal Interpolation and Data Normalization Methods in Detecting Pre-Earthquake Abnormal Temperature Increasing Phenomenon. Doctoral Disseration, Taiwan University, Taipei.

[59] Allameh-Zadeh, M., Ansari, A., Bahraminasab, A., Kaviani, K., Mahdavi, A., Ardakani, Mehr-nahad, H., Mehr-shahi, D., Niry, M.D., Reza Rahimi Tabar, M., Tabatabai, S., Taghavinia, N., Vesaghi, M. and Zamani, F. (2004) Mid-Infrared Radiation 
as a Short-Term Earthquake Precursor. arXiv: physics/0403003v1 [physics.geo-ph]

[60] Guangmeng, G. (2008) Studying Thermal Anomaly before Earthquake with NCPE data. The International Archive of the Photogrammetry, Remote Sensing and Spatial Information Sciences, Vol. 37, Part B8, ISPRS, Beijing.

[61] Tronin, A.A. (2010) Satellite Remote Sensing in Seismology. A Review. Special Issue Remote Sensing in Seismology, 2, 124-150. https://doi.org/10.3390/rs2010124

[62] Wei, C., Zhang, Y., Guo, X., Hui, S., Qin, M. and Zhang, Y. (2013) Thermal Infrared Anomalies of Several Strong Earthquakes. Scientific World Journal, 2013, Article ID: 208407. https://doi.org/10.1155/2013/208407

[63] Xiong, P., Shen, X., Gu, X., Meng, Q., Zhao, L., Zhao, Y., Li, Y. and Dong, J. (2015) Seismic Infrared Anomalies Detection in the Case of the Wenchuan Earthquake Using Bi-Angular Advanced along-Track Scanning Radiometer Data. Annals of geophysics, 58, Article No. S0217. https://doi.org/10.4401/ag-6706

[64] Freund, F.T., Takeuchi, A., Lau, B.W.S., Al-Manaseer, A., Fu, C.C., Bryant, N.A., Ouzounov, D. (2007) Stimulated Infrared Emission from Rocks: Assessing a Stress Indicator. eEarth, 2, 7-16. https://doi.org/10.5194/ee-2-7-2007

[65] Freund, F., Jhabvala, M., La, A., Shu, P., Tsay, S.C., Ouzounov, D. and Fei, Y. (2002) Mid-Infrared Luminescence Observed during Rock Deformation. Spring Meeting, American Geophysics Union, Washington DC, Paper No. T22B-03.

[66] Freund, F.F. (2003) Rocks That Crackle and Sparkle and Glow: Strange PreEarthquake Phenomena. Journal of Scientic Exploration, 17, 37-71

[67] Urusovskaya, A.A. (1969) Electric Effects Associated with Plastic Deformation of Ionic Crystals. Soviet Physics Uspekhi, 11, 631-644. https://doi.org/10.1070/PU1969v011n05ABEH003738

[68] Molotskii, M.I. (1980) Dislocation Mechanism for the Misra Effect. Soviet Technical Physics Letters, 6, 22-23.

[69] Molotskii, M.I. (1989) Electronic Excitation during the Plastic Deformation and Fracture of Crystals. In: Vol'pin, M.E., Eds., Soviet Scientific Reviews Series. Section $B$, Vol. 13, Harwood Academic Publishers, Amsterdam, 94 p.

[70] Liperovsky, V.A., Meister, C.V., Liperovskaya, E.V. and Bogdanov, V.V. (2008) On the Generation of Electric Field and Infrared Radiation in Aerosol Clouds Due to Radon Emanation in the Atmosphere before Earthquakes. Natural Hazards and Earth System Sciences, 8, 1199-1205. https://doi.org/10.5194/nhess-8-1199-2008 https://nhess.copernicus.org/articles/8/1199/2008/

[71] Khatiashvili, N.G. and Perel'man M.E. (1989) On the Mechanism of SeismoElectromagnetic Phenomena and Their Possible Role in the Electromagnetic Radiation during Periods of Earthquakes, Foreshocks and Aftershocks. Physics of the Earth and Planetary Interiors, 57, 169-177. https://doi.org/10.1016/0031-9201(89)90226-4

[72] Pulinets, S. and Ouzounov, D. (2011) Lithosphere-Atmosphere-Ionosphere Coupling (LAIC) Model-An Unified Concept for Earthquake Precursors Validation. Journal of Asian Earth Sciences, 41, 371-382. https://doi.org/10.1016/j.jseaes.2010.03.005

[73] Ouzounov, D., Pulinets, S., Hattori, K. and Taylor, P. (2018) Pre-Earthquake Processes: A Multidisciplinary Approach to Earthquake Prediction Studies. American Geophysical Union, Washington DC, 384 p. https://doi.org/10.1002/9781119156949 